\title{
Global Deployment of Geothermal Energy Using a New Characterization in GCAM 1.0
}

\author{
P Hannam \\ P Kyle \\ SJ Smith
}

September 2009

Pacific Northwest

NATIONAL LABORATORY

Proudly Operated by Battelle Since 1965 


\section{DISCLAIMER}

This report was prepared as an account of work sponsored by an agency of the United States Government. Neither the United States Government nor any agency thereof, nor Battelle Memorial Institute, nor any of their employees, makes any warranty, express or implied, or assumes any legal liability or responsibility for the accuracy, completeness, or usefulness of any information, apparatus, product, or process disclosed, or represents that its use would not infringe privately owned rights. Reference herein to any specific commercial product, process, or service by trade name, trademark, manufacturer, or otherwise does not necessarily constitute or imply its endorsement, recommendation, or favoring by the United States Government or any agency thereof, or Battelle Memorial Institute. The views and opinions of authors expressed herein do not necessarily state or reflect those of the United States Government or any agency thereof.

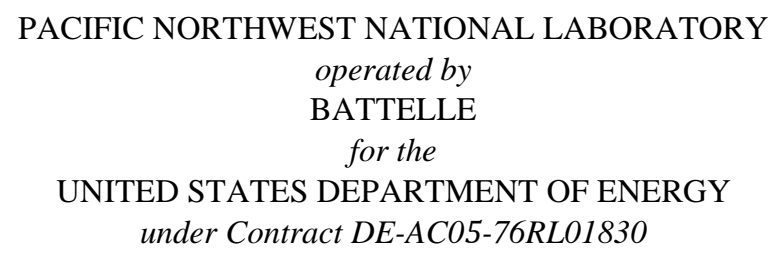

Printed in the United States of America

Available to DOE and DOE contractors from the Office of Scientific and Technical Information, P.O. Box 62, Oak Ridge, TN 37831-0062; ph: (865) 576-8401 fax: (865) 576-5728 email: reports@adonis.osti.gov

Available to the public from the National Technical Information Service, U.S. Department of Commerce, 5285 Port Royal Rd., Springfield, VA 22161 ph: (800) $553-6847$ fax: (703) 605-6900 email: orders@ntis.fedworld.gov online ordering: http://www.ntis.gov/ordering.htm 


\section{Global Deployment of Geothermal Energy Using a New Characterization in GCAM 1.0}

P. Hannam
P. Kyle
S. J. Smith

September, 2009

Prepared for the U.S. Department of Energy

under Contract DE-AC05-76RL0

Pacific Northwest National Laboratory

Richland, Washington 99352 


\section{Abstract}

This report documents modeling of geothermal energy in GCAM 1.0 (formerly MiniCAM) from FY2008 to FY2009, from the inputs to the U.S. Climate Change Technology Program report (Clarke et al., 2008a) to the present representation, which will be used in future work. To demonstrate the newest representation, we describe the procedure and outcome of six model runs that illustrate the potential role of geothermal energy in the U.S. and global regions through different futures of (a) climate policy (approximately a 450 ppmv pathway), (b) development and deployment of engineered, or enhanced, geothermal systems (EGS), and (c) availability of other low-cost, low-carbon electricity generation technologies such as nuclear energy and carbon capture and storage (CCS). Without a climate policy, conventional (hydrothermal) geothermal capacity expands in these scenarios by about tenfold by 2050, producing approximately 1.5 percent of global electricity in 2050 relative to $0.3 \%$ presently. Assumed resource base limitations constrain hydrothermal deployment after 2050 in all regions except Latin America; as a result, little growth is observed in the latter part of the century, and deployment is not responsive to climate policy. In contrast, advances allowing for deployment of EGS may greatly expand the role of geothermal over the upcoming century. Deployment of EGS appears sensitive to emissions prices and the characteristics of other electric generation technologies, such as expanded nuclear energy and CCS. When $\mathrm{CO}_{2}$ emissions are priced and nuclear energy and CCS are constrained in all regions, up to 10 percent of global electricity is produced by geothermal energy. EGS resources are most abundant in the United States, Western Europe, Latin America, and Southeast Asia, but this analysis suggests that it may be most important in regions with constraints on other low-carbon electric generation options such as nuclear energy or CCS. 


\section{Contents}

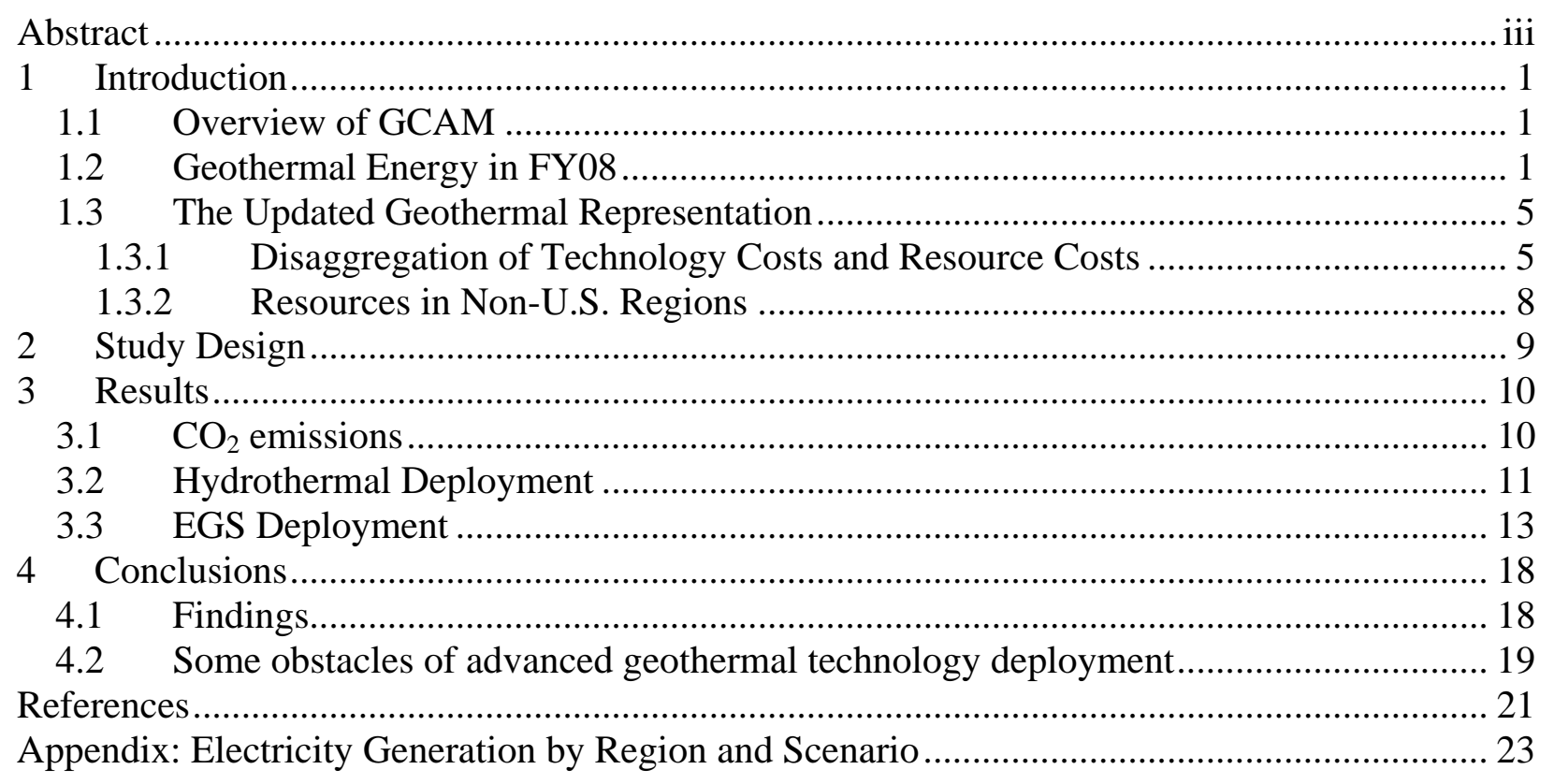




\section{Introduction}

The first part of this report documents the modeling approach and assumptions for geothermal energy in GCAM 1.0 (formerly MiniCAM), a global, integrated assessment model of energy, agriculture, land use, and climate change. Started in FY08 for the U.S. Climate Change Technology Program (CCTP), the purpose of this work is to understand the potential role of geothermal energy in the future market for electricity, in different scenarios of future climate policy and energy system technological evolution. The second half of the report presents results from six scenarios, analyzing the role of geothermal energy in reducing the costs of climate change mitigation. The report concludes by outlining important considerations for future work on geothermal modeling in integrated assessment.

\subsection{Overview of GCAM}

The analysis for this paper was conducted using the GCAM 1.0 integrated assessment model (Brenkert et al., 2003; Kim et al., 2006). GCAM is a dynamic-recursive, partialequilibrium model that links representations of global energy, agriculture, land-use, and climate systems. GCAM runs in 15-year timesteps from 1990 through 2095, and has 14 regions, one of which is the United States. While the present study focuses on dynamics within regional electricity sectors, the model calculates equilibria in each time period in all regional and global markets for energy goods and services, agricultural goods, land, and, where applicable, greenhouse gas (GHG) emissions.

Exogenous model inputs include service demand drivers (population and economic growth), exhaustible and renewable resource supplies, and characteristics of technologies involved in the production, transformation, delivery, and final consumption of energy. Multiple technologies may compete to provide any energy good or service, and market share is allocated to competing technologies on the basis of relative costs, using a logit choice mechanism (Clarke and Edmonds, 1993). The cost of each technology is calculated as the sum of levelized capital and O\&M costs and fuel or resource costs. Capital and O\&M costs are exogenous, and fuel costs are calculated from exogenous efficiencies and endogenous fuel prices. In the case of geothermal energy, the costs are calculated based on a combination of regional, exogenous supply curves that represent "resource" costs and technology. Model assumptions for scenario variables and technologies not investigated in this study can be found in Clarke et al. (2008a).

\subsection{Geothermal Energy in FY08}

This section describes the representation of geothermal energy as used in the 2008 CCTP scenarios (Clarke et al., 2008a) for the U.S. This is presented in order to document the methods and assumptions used in the 2008 CCTP scenarios. The next section will describe improvements to this representation that were subsequently implemented.

The geothermal energy representation used in the 2008 CCTP scenarios was based on cost curves provided by the National Renewable Energy Laboratory (NREL) for input to the MARKAL model (Petty and Porro 2007). The supply curves were converted to smooth curves for GCAM, using the following equation:

$$
\text { output }(\text { price })=\max \text { Re source } \times \frac{\text { price }^{\text {curveExponent }}}{\text { midprice } e^{\text {curveExponent }}+\text { price }^{\text {curveExponent }}}
$$


Where;

output $=$ geothermal electricity production

price $=$ electricity price

maxResource $=$ the maximum possible deployment of the resource

midprice $=$ the price at which half of the resource is used

curveExponent $=$ a shape parameter

The shape parameter (curveExponent) was calculated to minimize the deviation between the fitted curves and the NREL supply curves. Geothermal electricity was modeled as a single electric technology, with no distinction drawn between flash and binary technologies. "Hydrothermal” and "engineered geothermal resources" (hereafter, EGS; see MIT 2006) are represented as separate "subresources" of a single geothermal "resource." At any given market price, the share allocated to each subresource depends on the magnitude of each supply curve at that price. In the CCTP scenarios, the EGS subresource was only allowed in "advanced" renewable scenarios, as it was assumed that the very high capital costs and exploratory nature of the endeavor would prohibit deployment of the technology in the absence of some sort of technological breakthrough or policy incentive. Technological change was represented by assuming the resource supply curves shift downwards in cost over time, following the improvement multipliers in the NREL analysis. The NREL "Baseline" scenario was used as the GCAM reference technology, and the NREL “Target” scenario was used as the GCAM advanced technology. The Supply curves assumed for the United States are shown in Figure 1, below.

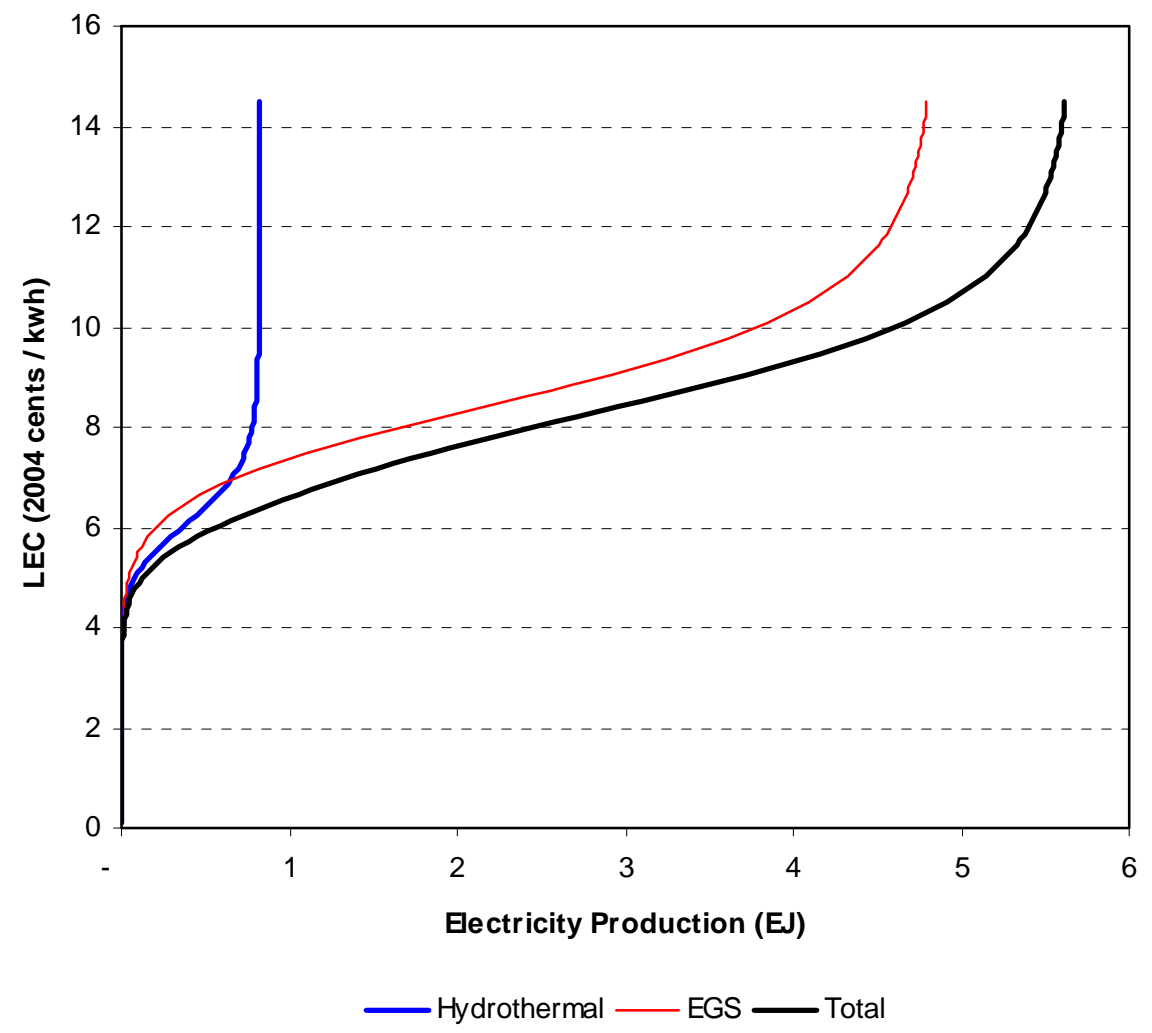

Figure 1. Geothermal resource supply curves for the United States, used in Clarke et al. (2008a) for the base year 2005. 
The same supply curve shape was assumed for all non-US regions, with the magnitude adjusted according to the resource potential in each region. For the FY08 model, the global resource potential magnitudes were based on the estimated economic potential by continent in Glitnir (2007). Because GCAM has 14 regions, a number of the continents (e.g. Asia) had to be disaggregated; separation of continents into regions was based on the geothermal electricity production in 2005 in each GCAM region (IEA, 2007a and 2007b). The exceptions were India and China, which were assumed to have the same geothermal potential as the U.S., as assumed by IEA (2008), in spite of having zero base year deployment. Table 1, below, shows the estimated potential for each region. EGS resources were scaled such that the ratio of EGS to hydrothermal resource was constant, and equal to about 6:1 for all regions. This is equal to the ratio in the U.S. implied by the NREL data.

Table 1. Maximum potential geothermal electricity production by GCAM region, in Clarke et al. (2008a).

\begin{tabular}{lcc} 
& $\begin{array}{c}\text { Hydrothermal } \\
\text { EJ }\end{array}$ & $\begin{array}{c}\text { EGS } \\
\text { EJ }\end{array}$ \\
\hline USA & 0.82 & 4.85 \\
Canada & 0.00 & 0.00 \\
Western Europe & 0.43 & 2.52 \\
Japan & 0.18 & 1.09 \\
Australia_NZ & 0.25 & 1.45 \\
Former Soviet Union & 0.02 & 0.14 \\
China & 0.82 & 4.85 \\
Middle East & 0.00 & 0.00 \\
Africa & 0.38 & 2.26 \\
Latin America & 1.04 & 6.14 \\
Southeast Asia & 0.94 & 5.56 \\
Eastern Europe & 0.00 & 0.00 \\
Korea & 0.00 & 0.00 \\
India & 0.82 & 4.85 \\
Total & $\mathbf{5 . 7 2}$ & $\mathbf{3 3 . 7 1}$ \\
\hline
\end{tabular}

As an additional technical point, the IEA energy balances (IEA, 2007a and 2007b), used for base year calibration, contain information on geothermal "input" energy as well as electric "output," with derived average efficiencies shown below in Table 2. Most regions in the IEA were apparently assigned a default value of $10 \%$. The electric output energy reported by IEA is used for calibration of historical data in the GCAM model. For simplicity all regions are assigned an efficiency of $10 \%$ such that deployment is a function of resource potential, and not efficiency. The role of improved efficiency over time is not investigated either in the CCTP analysis or the present study, although this could be examined if suitable data became available. Note that our assumption of $10 \%$ efficiency has no bearing on primary energy calculations. Primary energy in GCAM is calculated based on fossil energy displacement, and for geothermal electricity is equal to the geothermal electricity output divided by the average fossil electric efficiency.

Table 2. Average geothermal electric efficiencies by GCAM region, from IEA (2007a and 2007b). These are not used in GCAM due to lack of standardization between regions. 


\begin{tabular}{lc} 
& Efficiency \\
\hline USA & $19 \%$ \\
Canada & na \\
Western Europe & $10 \%$ \\
Japan & $10 \%$ \\
Australia_NZ & $16 \%$ \\
Former Soviet Union & $10 \%$ \\
China & na \\
Middle East & na \\
Africa & $10 \%$ \\
Latin America & $10 \%$ \\
Southeast Asia & $10 \%$ \\
Eastern Europe & na \\
Korea & na \\
India & na \\
\hline
\end{tabular}

This representation is simple and incorporates a number of assumptions due to the limited availability of current global EGS resource information. Scenarios in the CCTP study that included EGS tended to have quite large deployments of geothermal energy (see Figure 2, below); this prominence justified the current study, in order to refine the resource assumptions and the technology representation as described in the next section.

In the FY08 work, EGS resources were disaggregated to model regions using base year hydrothermal electricity production. Consultation with Jeffrey Tester (Cornell University) indicates that current hydrothermal deployment is a poor indicator of EGS resource availability. In fact, four regions of the world (Canada, Eastern Europe, Korea, and the Middle East) were previously assumed to have zero EGS resources, due to this allocation method, though their potential is unlikely to be zero.

Finally, the representation used in the CCTP study was parameterized in such a way that all costs were assumed to be in the resource supply curves with no explicit representation of capital costs. The practical implication is that at low levels of deployment relative to maximum resources in each region geothermal electricity is produced for very low cost and the steepness of the supply curves can present difficulties for the model solution algorithms. In the prior representation (Figure 1), as the quantity approaches zero, the curve becomes asymptotic — small changes in quantities produce large changes in prices. Due to the large amounts of geothermal resources assumed available in most regions of the world, relative to base year deployment, this is the most relevant part of the supply curve. The next section will discuss the improvements made to geothermal to address theses issues. 


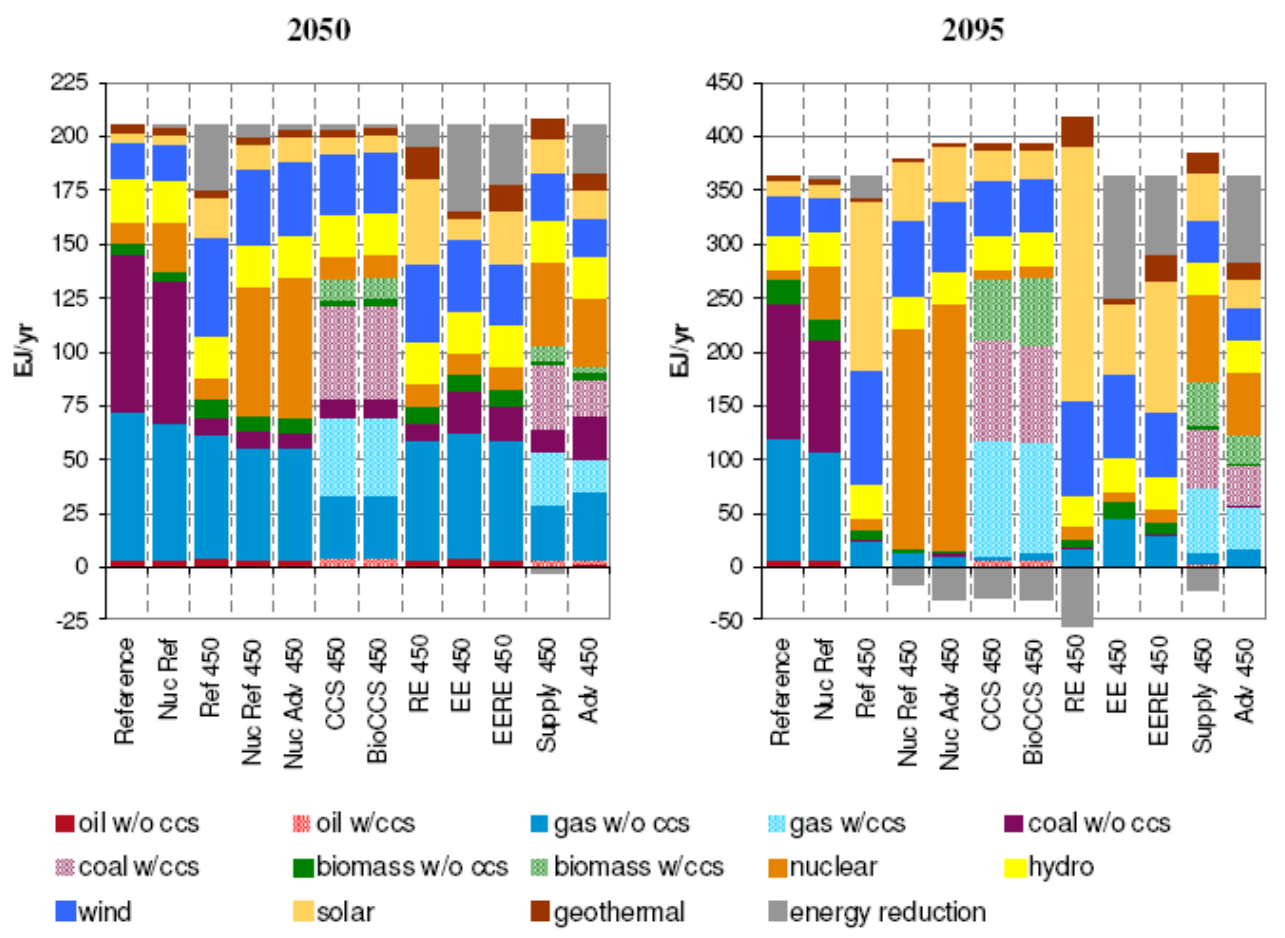

Figure 2. Global electricity production across 450 ppmv stabilization scenarios: 2050 and 2095. Source: Figure 5.5 in Clarke et al. (2008a).

\subsection{The Updated Geothermal Representation}

The new geothermal representation differs from the one used in the CCTP study in two key ways: (1) capital and resource costs are disaggregated, providing an effective price floor for geothermal, and necessitating adjustments to the supply curves; (2) further research justified adjusting the maximum EGS resources and the allocations of maximum hydrothermal resources within continents. The global total EGS resources are now slightly lower (from 34 EJ to 30 EJ); however, the new representation allows geothermal energy in all regions except for South Korea.

\subsubsection{Disaggregation of Technology Costs and Resource Costs}

The cost of any technology in GCAM consists of the sum of two types of cost components: a combined capital and O\&M cost, and a fuel cost, or in this case a resource cost. The capital and O\&M costs are exogenous, and are calculated based on assumptions for a representative power plant for the overnight capital cost and fixed capital charge rate, the fixed and variable operations and maintenance $(\mathrm{O} \& \mathrm{M})$ costs, and the capacity factor. Capital costs are fixed for each time period and do not change with deployment. Furthermore, capital costs in GCAM are generally assumed equal across all regions within any time period; that is, the cost of building a new power plant is assumed not to vary by location.

In contrast, the fuel cost is endogenous, and consists of the price of each input fuel multiplied by an exogenous input-output coefficient, or the number of units of energy input required to produce each unit of electric energy. Fuel prices are determined through several mechanisms, depending on the fuel used, but are assumed, at any given point in time, to have increasing marginal costs with production. Moreover, energy costs can vary by region, particularly for renewable resources that cannot be traded between regions. 


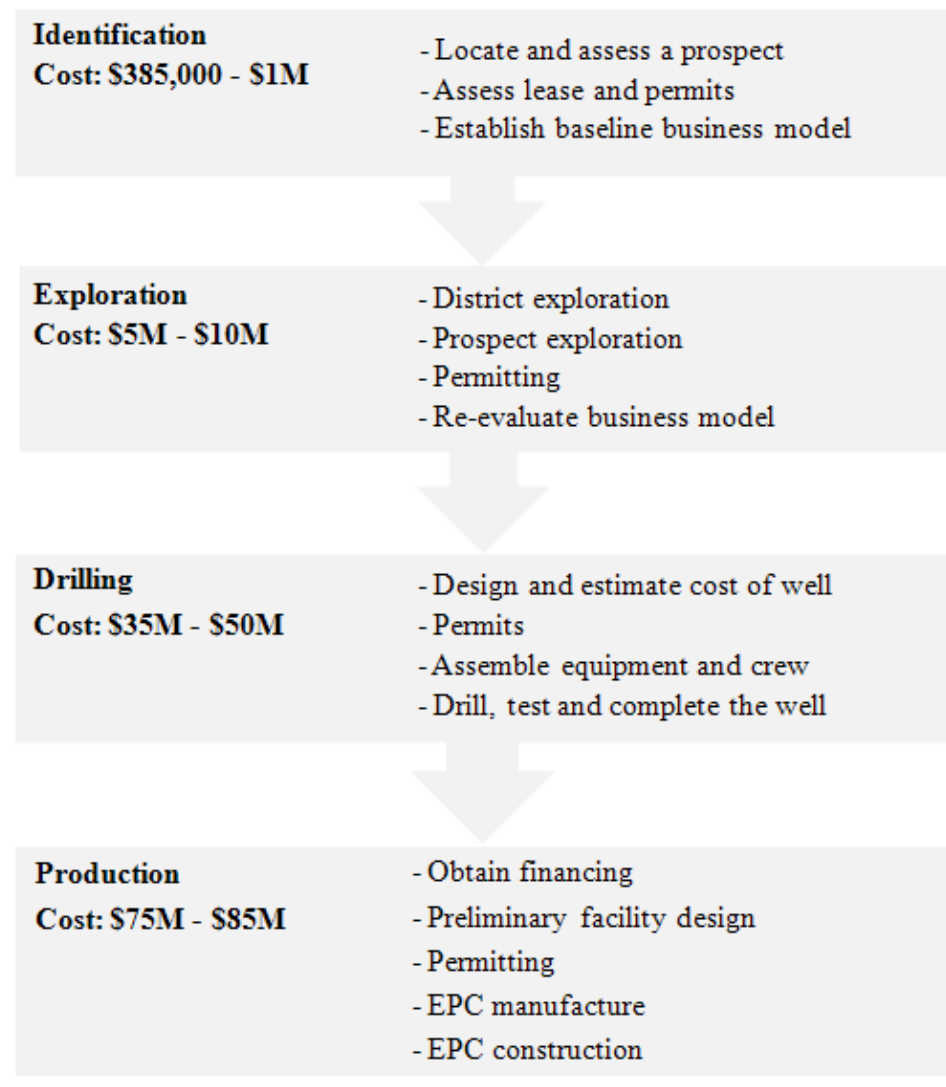

Figure 3. Phases of geothermal project development for a representative 50-MW facility. Source: Adapted from Figure 10 of Deloitte (2008).

For geothermal electricity generation, we disaggregate costs into a resource component and a technology component. Technology costs are those that are assumed to not vary by region and not increase with deployment, although technology costs are assumed to decline over time due to technological improvements. The costs of geothermal projects have been disaggregated into four components for a representative 50-MW geothermal facility by Deloitte (2008) and are shown in Figure 3. Each of these components is assigned to GCAM category as shown in Table 3. The calculated base technology cost (levelized capital and O\&M costs per unit of electricity output) is then deducted from each point of the supply curves provided by Gian Porro (NREL), and these residual curves are used as the resource supply curves input to GCAM. The new supply curves (including base technology costs) are shown in Figure 4. Note that technological change is assumed to take place both in the technology and resource costs, so both the price "floor" and the supply curve will shift downward over time. Note also that, for simplicity, we assume linear supply curves (in contrast to the logistic curves used for other resources). This assumption is most relevant for the EGS resource where differences in the shape of the lower portion of the resource cost curve can have a noticeable impact on the final model results. If more detailed resource information becomes available a different resource representation may be appropriate. 
Table 3. Assumed costs per kilowatt of geothermal by component in Deloitte (2008), and disaggregation between technology and resource costs in GCAM. The technology costs, or production-related costs, are assumed constant for all regions and do not increase with deployment (i.e. marginal costs are constant). The Mid-range costs are assumed in this study. The resource costs for geothermal in GCAM are included as supply curves instead of as point estimates (shown in the table below for reference only).

\begin{tabular}{|l|l|ccc|}
\hline Phase & MiniCAM category & Low cost & Mid cost & High cost \\
& & $\mathbf{2 0 0 4 \$ / k w ~}$ & $\mathbf{2 0 0 4 \$ / k w ~}$ & $\mathbf{2 0 0 4 \$ / \mathbf { k w }}$ \\
\hline \hline Identification & resource & 7.7 & 12 & 20 \\
Exploration & resource & 100 & 150 & 200 \\
Drilling & resource & 700 & 850 & 1000 \\
Production & non-fuel & 1500 & 1600 & 1700 \\
\hline Total & & 2,308 & 2,612 & 2,920 \\
\hline
\end{tabular}

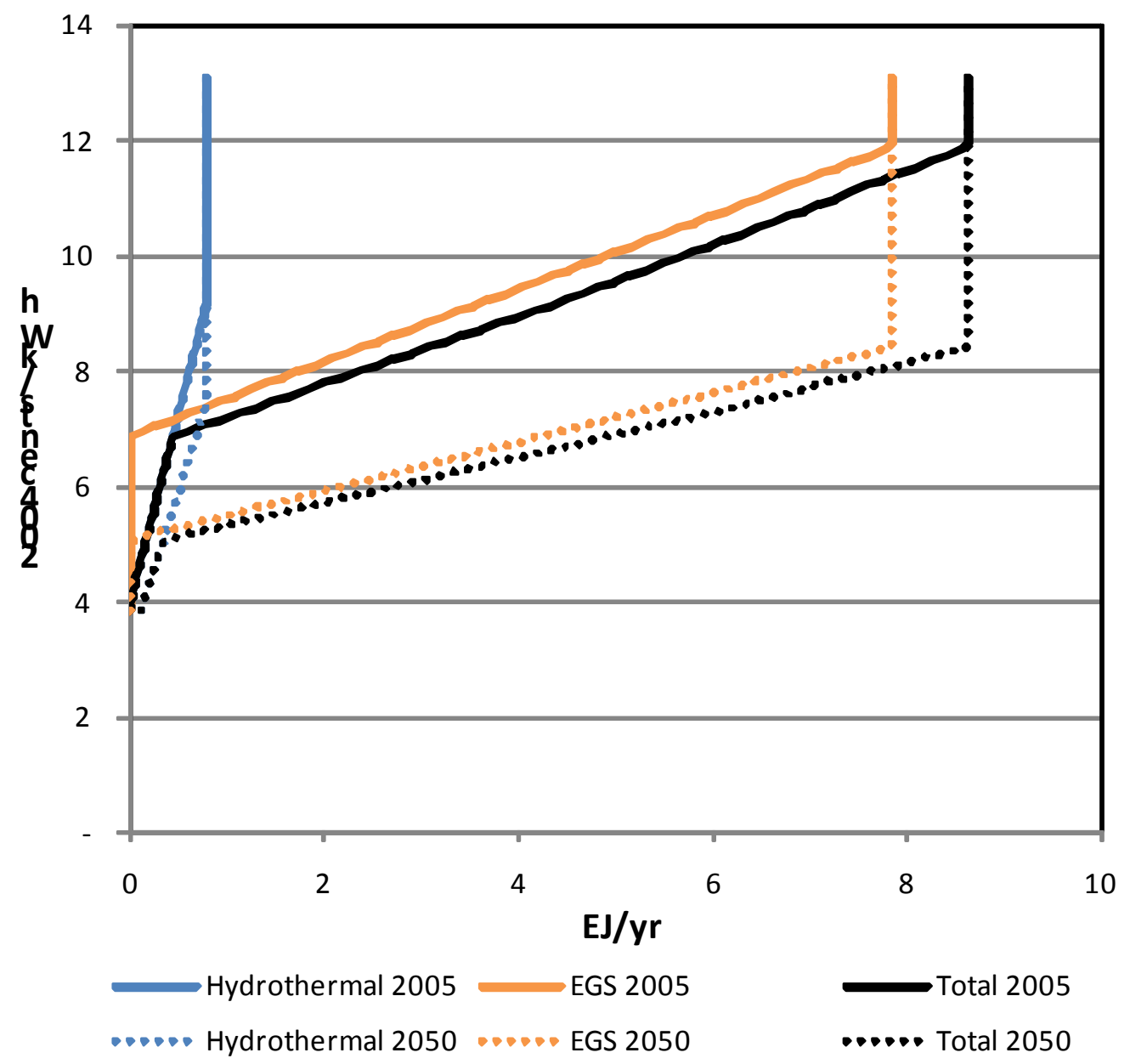

Figure 4. The effective U.S. geothermal supply curves (including resource and production costs) used in the GCAM model for the present analysis. Also shown is the shift in the assumed supply curves in 2050. 


\subsubsection{Resources in Non-U.S. Regions}

While the U.S. region has typically been the focus of EERE-funded research at JGCRI, it is becoming increasingly apparent that non-U.S. regions are critical for understanding the role of technology as a means to address climate change and, therefore, estimates for other global regions were implemented for use in the CCTP scenarios (e.g. Clarke et al., 2008b). In order to assure that the representation of geothermal technologies would be useful for future analysis, we also wished to improve the representation of geothermal resources in non-U.S. regions.

However, initial research indicated that there are no consensus estimates of potential geothermal resources by region and that estimates that do exist are quite inconsistent. Given the state of this data, it was decided to benchmark estimates in other regions to the assumed potential represented in the U.S., given that the supply curves for the U.S. are well documented (Petty and Porro 2007). Estimates of the potential EGS resources by GCAM region are shown in Table 4 for a variety of studies. Note that the EPRI (1978) is a measure of technical potential, and though detailed and theoretically sound at the time of production, is now thought to be out of date (R. Bertani, unpublished report; J. Tester, pers. comm.).

Table 4. Potential geothermal resources by several estimates, relevant for estimating potential of geothermal in non-U.S. regions.

\begin{tabular}{|c|c|c|c|c|c|c|}
\hline \multirow[b]{2}{*}{ MiniCAM region } & \multicolumn{2}{|c|}{ Theoretical potential } & \multicolumn{4}{|c|}{ Maximum economic supply (EJ/yr) } \\
\hline & $\begin{array}{c}\text { EPRI total } \\
\text { (thous EJ/yr) }\end{array}$ & $\begin{array}{c}\text { Bertani } \\
\text { total (EJ/yr) }\end{array}$ & $\begin{array}{c}\text { Glitnir } \\
\text { hydrothermal }\end{array}$ & Bertani EGS & $\begin{array}{c}\text { MiniCAM } \\
\text { hydrothermal }\end{array}$ & $\begin{array}{c}\text { MiniCAM } \\
\text { EGS }\end{array}$ \\
\hline USA & 138.4 & 37.0 & 0.88 & $\begin{array}{l}18.92 \\
\end{array}$ & $\begin{array}{l}0.79 \\
\end{array}$ & 27.85 \\
\hline Canada & 127.1 & 34.0 & 0.01 & 0.32 & 0.01 & 0.13 \\
\hline Western Europe & 44.3 & 12.0 & 0.39 & 4.73 & 0.35 & 1.96 \\
\hline Japan & 22.3 & 6.0 & 0.06 & 0.63 & 0.06 & 0.26 \\
\hline Australia_NZ & 8.5 & 2.0 & 0.27 & 0.95 & 0.24 & 0.39 \\
\hline Former Soviet Union & 67.0 & 18.0 & 0.28 & 2.84 & 0.25 & 1.18 \\
\hline China & 160.8 & 39.0 & 0.16 & 1.58 & 0.14 & 0.65 \\
\hline Middle East & 23.2 & 6.0 & 0.06 & 0.63 & 0.06 & 0.26 \\
\hline Africa & 104.0 & 25.0 & 0.42 & 0.95 & 0.38 & 0.39 \\
\hline Latin America & 343.6 & 91.0 & 1.14 & 4.73 & 1.02 & 1.96 \\
\hline Southeast Asia & 142.4 & 41.0 & 0.63 & 6.31 & 0.57 & 2.62 \\
\hline Eastern Europe & 1.0 & 0.0 & 0.08 & 0.95 & 0.07 & 0.39 \\
\hline Korea & 6.7 & 4.0 & 0.00 & 0.00 & 0.00 & 0.00 \\
\hline \begin{tabular}{|l} 
India \\
\end{tabular} & 4.0 & 1.0 & 0.06 & 0.63 & 0.06 & 0.26 \\
\hline \begin{tabular}{|l} 
Total \\
\end{tabular} & 1193.3 & 316.0 & 4.46 & 44.15 & 4.01 & 18.31 \\
\hline
\end{tabular}

The Bertani estimates are from a dataset developed for the 2009 GEA World Outlook as part of the IPCC's exercise in generating consensus estimates of hydrothermal and EGS resources by region (R. Bertani, International Geothermal Association; unpublished data). The Glitnir estimates of hydrothermal resources are compiled from the International Geothermal Energy Association and other sources, and were presented as global economically recoverable resources in six continents (Glitnir 2007). These resource estimates by continent were disaggregated to GCAM regions according to each GCAM region's share of the continental total geothermal resources as estimated in the Bertani dataset. 
The estimated maximum economic potential resources in the U.S. presented by both Glitnir (hydrothermal) and Bertani (EGS) are larger than the high points of the hydrothermal and EGS cost curves presented by Petty and Porro (2007; 0.79 EJ/yr and 7.85 EJ/yr, respectively). The criteria used for assessing what resources are "economic" in the former two sources are unclear (in part due to the preliminary nature of some of this data). It is also not clear how these resource potentials would fit with the supply curves assumed for the U.S. Therefore, estimates in each region other than the U.S. are adjusted downward by the ratio of U.S. maximum resource estimates in the NREL supply curves, to the Glitnir (2007) maximum potential for hydrothermal resources, and to the Bertani estimates for EGS, respectively. The resources represented in GCAM in this report may therefore be conservative because of this scale-down procedure, particularly for EGS resources. In any case, the model input data can be updated when new information becomes available.

We now use this improved representation to examine the potential role of geothermal energy in the future.

\section{Study Design}

The present study presents six scenarios, with each outlined in Table 5, below. In summary, the scenarios consist of all possible permutations of two futures of climate policies, two geothermal technology futures, and two technology futures relevant to the remainder of the electricity system.

Table 5. Scenarios analyzed in this study.

\begin{tabular}{|l|llll|}
\hline Scenario Name & Geothermal Technology & Other Technology & Climate Policy & Type \\
\hline \hline Hydro: & Hydrothermal Geothermal only & Reference Electric Sector & No Policy \\
\hline EGS: & EGS Geothermal available & Reference Electric Sector & No Policy \\
\hline Hydro CP: & Hydrothermal Geothermal only & Reference Electric Sector & Climate Policy \\
\hline EGS CP: & EGS Geothermal available & Reference Electric Sector & Climate Policy & \\
\hline Hydro CP NoNucCCS: & Hydrothermal Geothermal only & NoNucCCS & Climate Policy & Sensitivity \\
\hline EGS CP NoNucCCS: & EGS Geothermal available & NoNucCCS & Climate Policy & Sensitivity \\
\hline
\end{tabular}

"Hydro" scenarios assume that EGS never becomes available, and that hydrothermal costs decrease by about $0.45 \%$ per year through 2050 , and $0.25 \%$ per year thereafter. "EGS" scenarios assume an accelerated rate of decrease for hydrothermal costs to 2050 (about $0.7 \%$ per year), and that EGS becomes available starting in 2020. EGS costs are assumed to decline at $0.6 \%$ per year from 2020 to 2035, at $0.4 \%$ per year between 2035 and 2050, and at $0.25 \%$ per year thereafter (all geothermal cost reductions to 2050 are from G. Porro). For comparison, the annual improvement rates assumed for fossil-fired electric generation technologies in these scenarios are generally about $0.3 \%$ to $0.4 \%$.

In the "CP" scenarios, $\mathrm{CO}_{2}$ emissions are priced starting at $\$ 9.40$ per ton $\mathrm{CO}_{2}$ in 2020 (2005 USD) and increasing at 5\% per year thereafter, through 2095. This carbon price path is used as a means of comparing the impact of a carbon price in a consistent manner across these different technology scenarios. The implications of this particular price path for carbon dioxide emissions and concentration are shown in the next section.

Finally, additional policy scenarios are run as part of a sensitivity analysis to examine a case where alternative low-carbon electricity sources are significantly limited, although other low-carbon sources such as wind and solar are still assumed to be available. The sensitivity 
analysis also assumes that nuclear remains part of the energy mix but does not expand beyond present-day deployment and that CCS is not allowed at any point.

While each scenario run contains information for the entire energy and agricultural systems in each region, the present study focuses only on geothermal energy, total electricity generation, and $\mathrm{CO}_{2}$ emissions from the electricity sector in each region. Other aspects, such as the role of geothermal in facilitating electrification of end-use demands, are not addressed here. The potential for added value of geothermal as a sequestration source by using supercritical $\mathrm{CO}_{2}$ from coal-burning power plants as the working fluid in EGS is also not considered here, though it is further discussed in MIT (2006).

\section{Results}

\section{$3.1 \mathrm{CO}_{2}$ emissions}

Figure 5 shows $\mathrm{CO}_{2}$ emissions and concentrations for all scenarios without EGS available, from 1990 to 2095, in order to set the context for the analysis. Without a climate policy, global $\mathrm{CO}_{2}$ emissions increase substantially through the end of the century, and the $\mathrm{CO}_{2}$ concentrations approach 750 ppmv by the end of the century. The magnitude of the emissions reductions stimulated by the carbon price depends on the abatement technologies available; with nuclear power and CCS available, the steadily increasing carbon-tax in this policy produces peak $\mathrm{CO}_{2}$ concentrations in 2065, with concentrations falling to approximately $450 \mathrm{ppmv}$ at the end of the century. Without expanded nuclear power or CCS available, emissions mitigation is more costly, resulting in greater emissions than the previous case under the same carbon price. In this latter case, concentrations stabilize in 2080 at about 520 ppmv.

These technology scenarios are presented in order to emphasize that the future $\mathrm{CO}_{2}$ emissions, $\mathrm{CO}_{2}$ concentrations, and the economic responses to $\mathrm{CO}_{2}$ emissions prices are all highly dependent on both policy and technology. The policies analyzed describe two sharply divergent scenarios: one in which climate concerns never influence the energy system in spite of the climate-related impacts that would be occurring, and another in which all nations agree to share a common $\mathrm{CO}_{2}$ emissions price starting some time in the next decade (regardless of how feasible this outcome is in actuality). Similarly, the technology scenarios describe a wide range of plausible alternatives: one with large-scale central technologies available for $\mathrm{CO}_{2}$ mitigation, with no non-economic limits to deployment, and another where these technologies are simply not allowed. The purpose of this analysis is to examine the role of geothermal energy across the three broadly divergent scenarios described in Figure 5, and in particular, to focus on the role of EGS. The remainder of the analysis addresses several questions pertinent to geothermal energy; in particular, what is the future of geothermal energy with and without EGS? And, what is the role of climate policy and the availability of nuclear energy and CCS in the future expansion of geothermal energy? 

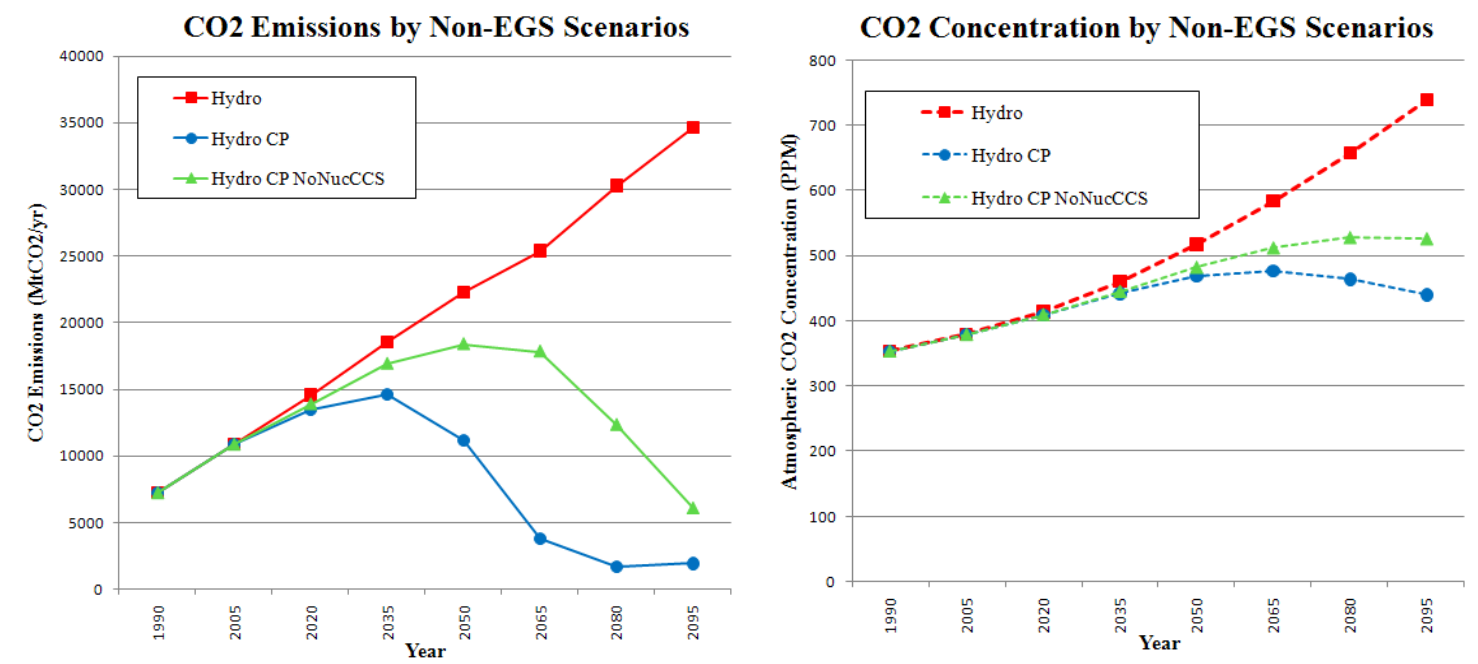

Figure 5: $\mathrm{CO}_{2}$ emissions and concentrations for scenarios where EGS is unavailable. The scenario labeled "hydro" is the reference case with no carbon price and the scenarios labeled "-CP" include the carbon price path outlined in the text.

\subsection{Hydrothermal Deployment}

All of the scenarios show significant growth in hydrothermal deployment above current levels with or without a carbon policy. As global electricity demand grows, so does hydrothermal generation in each GCAM region where resources exist; however, the assumed limits of hydrothermal resource potential in each region constrain hydrothermal's share of total electricity generation. Little growth is observed after midcentury in the U.S. and most other regions.

In 2005, geothermal electricity generation in the U.S. comprised less than one half of one percent of the total electricity generation. In the Hydro scenario (absent both a carbon policy and EGS), hydrothermal electricity generation between 2005 and 2050 grows by over eleven times, increasing its share of total national electricity generation to almost three percent (see Figure 6). The presence of a climate policy does enhance geothermal growth further, but the increase is modest - only between 10 and 15 percent of the geothermal generation observed without a climate policy. The scenarios demonstrate that, given the cost curves assumed for geothermal, and the assumptions for cost decreases, there is a large amount of geothermal energy that will become economical in the next few decades, without a climate policy. However, because the resource limits assumed in this study are approached even without a climate policy, the effect of a climate policy on the deployment of hydrothermal is small.

As a result of approaching the resource limits, while geothermal generation grows substantially between 2005 and 2050, generation grows only slightly between 2050 and 2095 in all scenarios absent EGS (Figure 6). Therefore, even as electricity prices and demand continue to rise, the scenarios show geothermal generation leveling off. The net result is that the share of geothermal in the electric sector falls between 2050 and 2095. In summary, for the U.S., hydrothermal geothermal expansion could contribute substantively to electricity demand growth, but the resource base is not abundant enough to keep up with long term demand growth. 

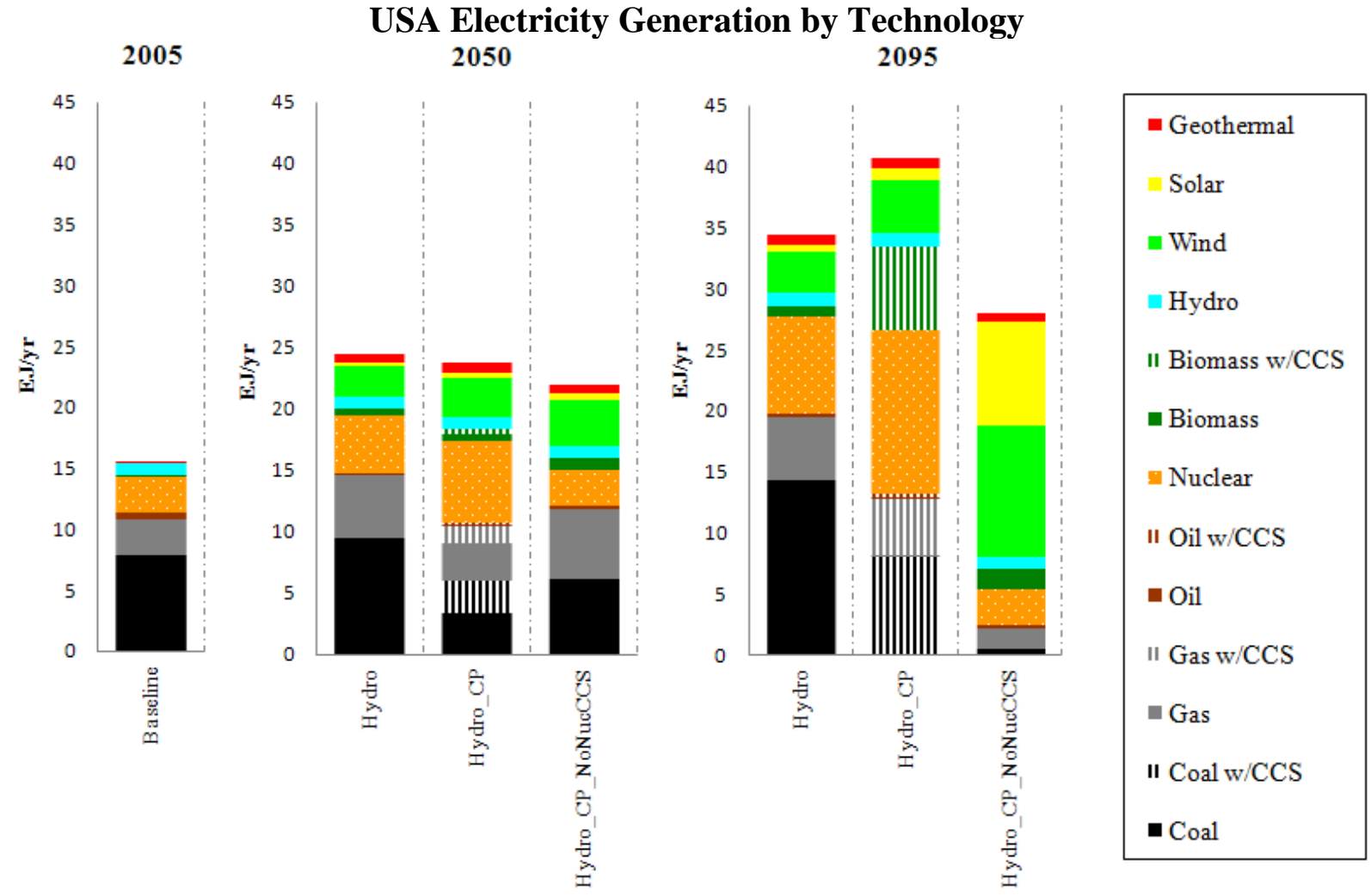

Figure 6: Electricity generation in the United States by Technology for scenarios where EGS is not available

Globally, the results show the same patterns as in the U.S.: deployment is constrained by assumed resource availability, even with a high carbon price. The plot in Figure 7, below, presents hydrothermal geothermal deployment over time for each of the GCAM regions for the Hydro and Hydro_CP scenarios without EGS. In the Hydro scenario, rapid geothermal growth until mid-century in most regions is followed by a leveling off as the available resources are developed. Latin America is a notable exception since hydrothermal deployment increases throughout the timeframe of the model run and does increase in response to a climate policy. Overall, Figure 7 supports the assertion that a climate policy does not drastically impact the rate, or maximum level, of deployment of geothermal electricity when hydrothermal alone is available. It should be reiterated that our estimates of the maximum resource bases by region are in agreement with published estimates (Glitnir, 2007), but as cost curves do not exist for nonU.S. regions, we have assumed the same shape of cost curves as is assumed for the U.S. Therefore, regional differences in deployment rates of geothermal (i.e. how fast each region approaches its assumed maximum level) reflect the growth of each region's electric sector, regional electricity prices, and prices of competing electric generating technologies in each region. 

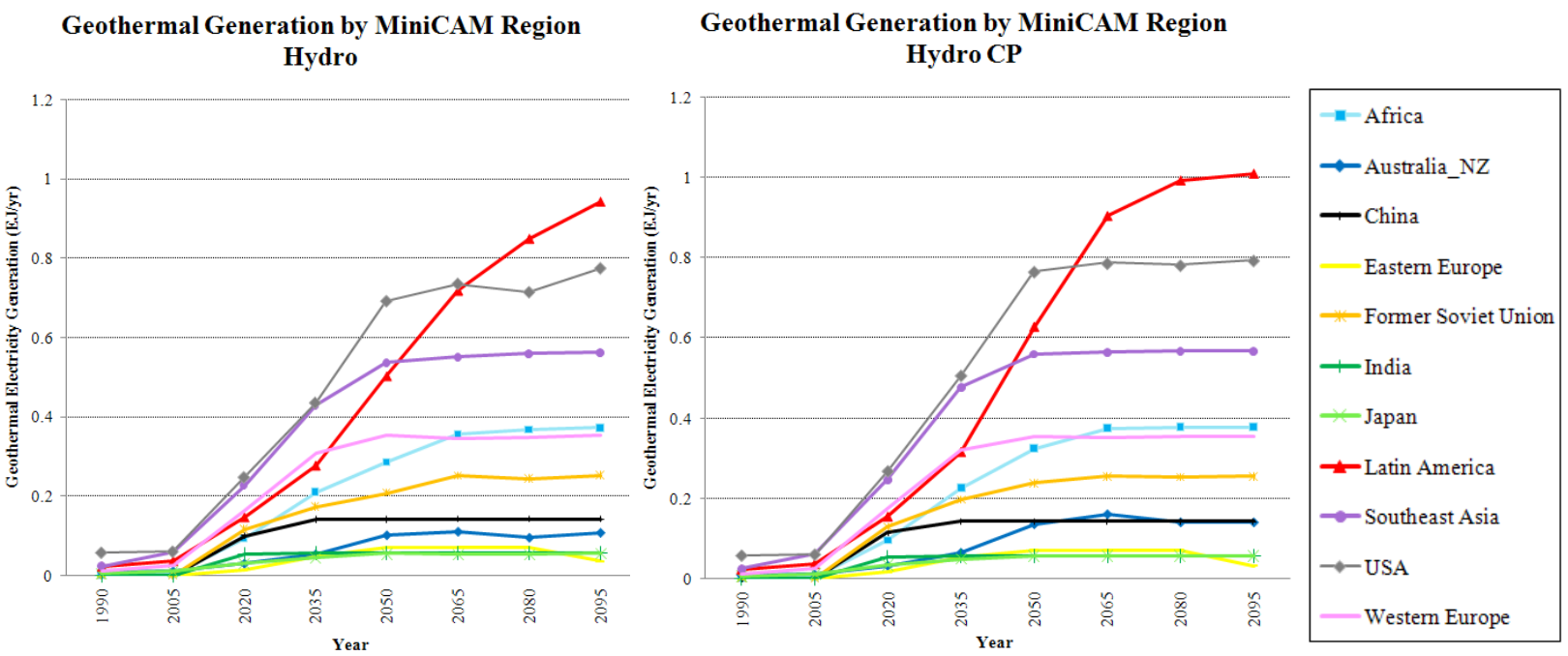

Figure 7: Hydrothermal deployment with and without a Carbon Policy for each GCAM region

High upfront capital costs and difficulties in securing financing, detailed in Deloitte (2008), presently constrain U.S. deployment of hydrothermal resources to less than 5 percent of the maximum economic hydrothermal potential (Glitnir, 2007; Deloitte, 2008). Least developed countries in particular face the most daunting challenges in covering incremental costs of highcapital renewable energy projects, relying on existing low-carbon financing mechanisms like the Clean Development Mechanism. These funds are severely limited, and are faced with administrative and bureaucratic obstacles that historically have deterred less developed countries from seeking upfront equity needed to finance the project (Chandler 2008, World Bank 2008). The growth in hydrothermal energy in the U.S. and all other regions observed in this study is contingent on the assumption that such development obstacles are overcome. This might happen through successful government policies or decreases in the level of risk (and associated financing challenges) of geothermal projects from learning-by-doing, for instance. In any case, the hydrothermal expansion observed in this study is still only capable of supplying a small portion of future electricity demand. Irrespective of a carbon tax and policies constraining nuclear and CCS deployment, hydrothermal geothermal energy never accounts for more than 2 percent of electricity globally, with the share consistently decreasing after 2050. The availability of EGS causes a major change in the role of geothermal energy in the global, and U.S., energy systems, as is outlined in the following sections.

\subsection{EGS Deployment}

Availability of EGS results in a much larger share of geothermal electricity generation with and without a climate policy, shown for the U.S. in Figure 8. In contrast to hydrothermalonly scenarios, the presence of a climate policy here results in significant additional growth of geothermal electricity generation. The scenario constraining the use of nuclear and CCS results in geothermal producing over a quarter of global electricity by 2095, indicating the potentially competitive nature of this resource with a high carbon price and unavailability of other low-cost, low-carbon alternatives.

In the absence of a climate policy, the scenario with EGS results in twice as much geothermal generation as the hydrothermal-only scenario in 2095. Here, geothermal accounts for 
nearly 3 percent of electricity generated. A climate policy, availability of EGS, and constrained nuclear and CCS results in over 40 times current geothermal deployment by 2050 (from $0.3 \%$ to $8 \%$ of generation share), and 135 times growth by 2095 (to over $27 \%$ generation share). EGS allows for geothermal generation to grow substantially after the hydrothermal potential has been exploited. In these scenarios, EGS is competitive with other forms of energy and maintains a growing share of electricity generation as electric demand grows, the $\mathrm{CO}_{2}$ price increases, and EGS costs are assumed to decrease. Note that the share of EGS will also be sensitive to the assumed rate of cost decrease over time.

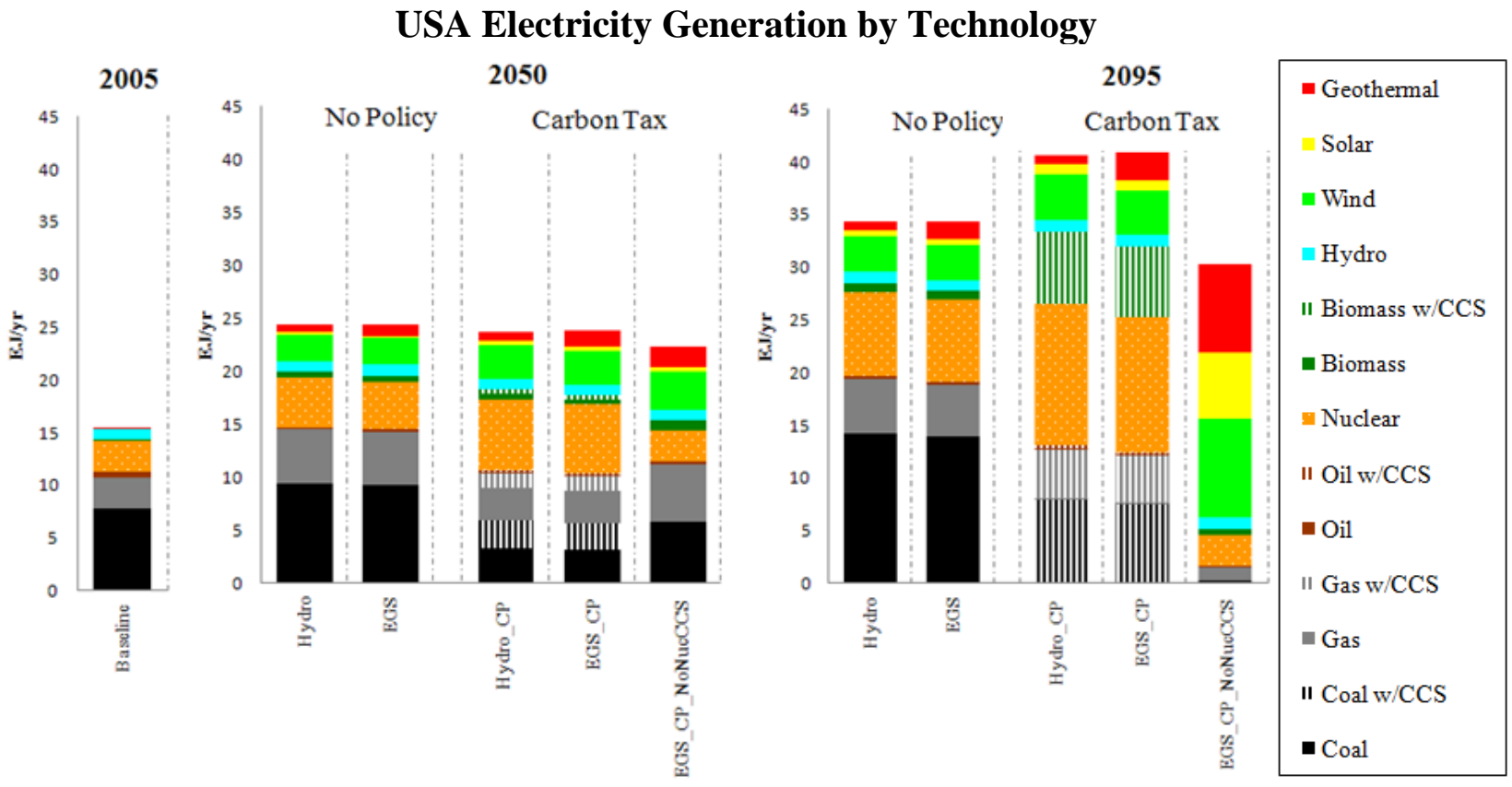

Figure 8: US electricity generation by technology comparing Hydro and EGS cases with and without climate policies and sensitivity analysis

In these scenarios with limited options for large-scale, low-emissions power generation, EGS supplies comparable amounts of electricity as wind and solar in many regions. As well, because geothermal technologies produce baseload (not intermittent) power, geothermal avoids some of the still-uncertain additional costs and technical challenges that would be presented by large-scale deployment of wind and solar energy. In GCAM these challenges are captured through backup- and storage-related cost penalties assessed to wind and solar technologies, assumed to increase with capacity share (see Clarke et al. 2008a). However, it isn't known what portion of the electric load could reasonably be supported by intermittent renewables (see U.S. DOE 2008). Constraints on wind and solar, or steeper penalties than are assumed in this study, would imply an even more prominent role for EGS. It is also worth pointing out that constraints on nuclear and CCS could allow EGS to play an especially significant role in the electricity growth of regions where nuclear may remain unavailable, or where a lack of accessible storage reservoirs may make CCS uneconomical (e.g. Japan, Korea, or India).

The combination of a global climate policy and availability of EGS could stimulate large deployments of geothermal energy relative to regional generation in Southeast Asia, Latin America and Western Europe, as was observed in the U.S. scenarios discussed above. Under this 
scenario, India, Africa, China, Former Soviet Union, Australia and New Zealand, and Japan experience moderate levels of geothermal deployment (Figure 9). Constraints on nuclear energy and CCS technology do not increase geothermal deployment in all regions; India, China, and Africa all showed very little response. These regions represent potentially very important economies over the upcoming century, and are discussed more specifically below.
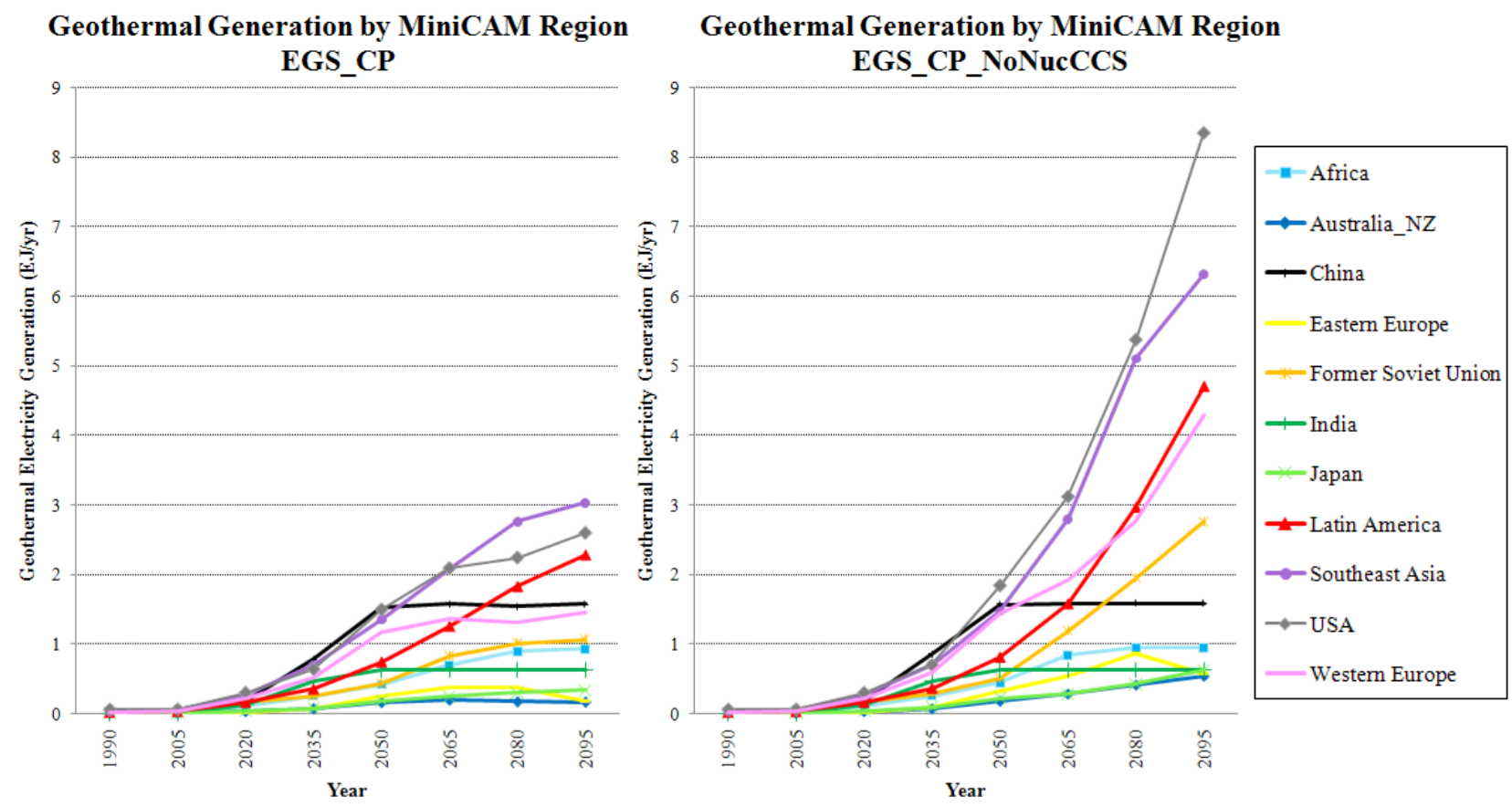

Figure 9: The effect of nuclear and CCS constraints on global geothermal deployment

Western Europe is of particular note because of its role as a region already implementing climate targets, and because of its reliance on nuclear power. In the EGS_CP scenario, geothermal comprises about 7 percent of electricity generation by 2050. Because of nuclear's prominent role in Western Europe's electricity system, and its anticipated growth, constraining nuclear and allowing EGS results in a three-fold increase in geothermal generation, and a fourfold increase in the geothermal grid share. Under this scenario, constraints on the use of nuclear and CCS would result in geothermal becoming the largest electricity source in the region.

Southeast Asia and Latin America are also of interest, because both consist of economies that are assumed to grow very rapidly in the upcoming century; in Southeast Asia, much of this growth takes place between 2050 and 2095. Both of these regions also have abundant geothermal resources. In the EGS_CP scenario, both regions generate about 5 percent of their electricity in 2095 with geothermal (see Figure 10). In terms of physical quantities, Southeast Asian geothermal generation is $3 \mathrm{EJ}(100 \mathrm{GW})$ and Latin American geothermal generation is $2.3 \mathrm{EJ}$ (77 $\mathrm{GW}$ ) - this is approximately equal to the entirety of Latin American electricity production from all sources in 1990, or from all hydroelectricity in the region at present. As with Western Europe, Southeast Asian and Latin American geothermal generation doubles, and the grid share triples when CCS and nuclear expansion are constrained. 


\section{Southeast Asia Electricity Generation by Technology}
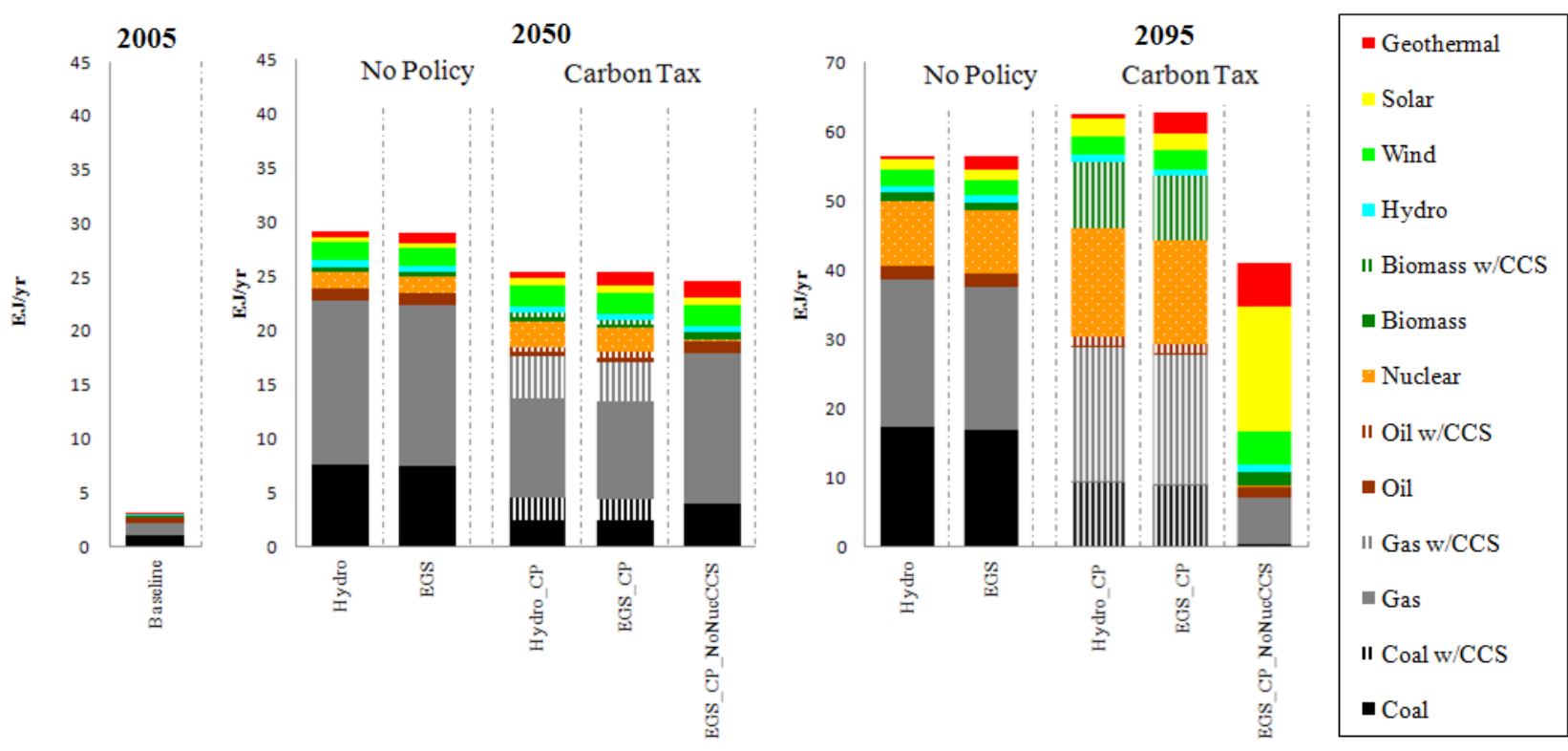

Latin America Electricity Generation by Technology
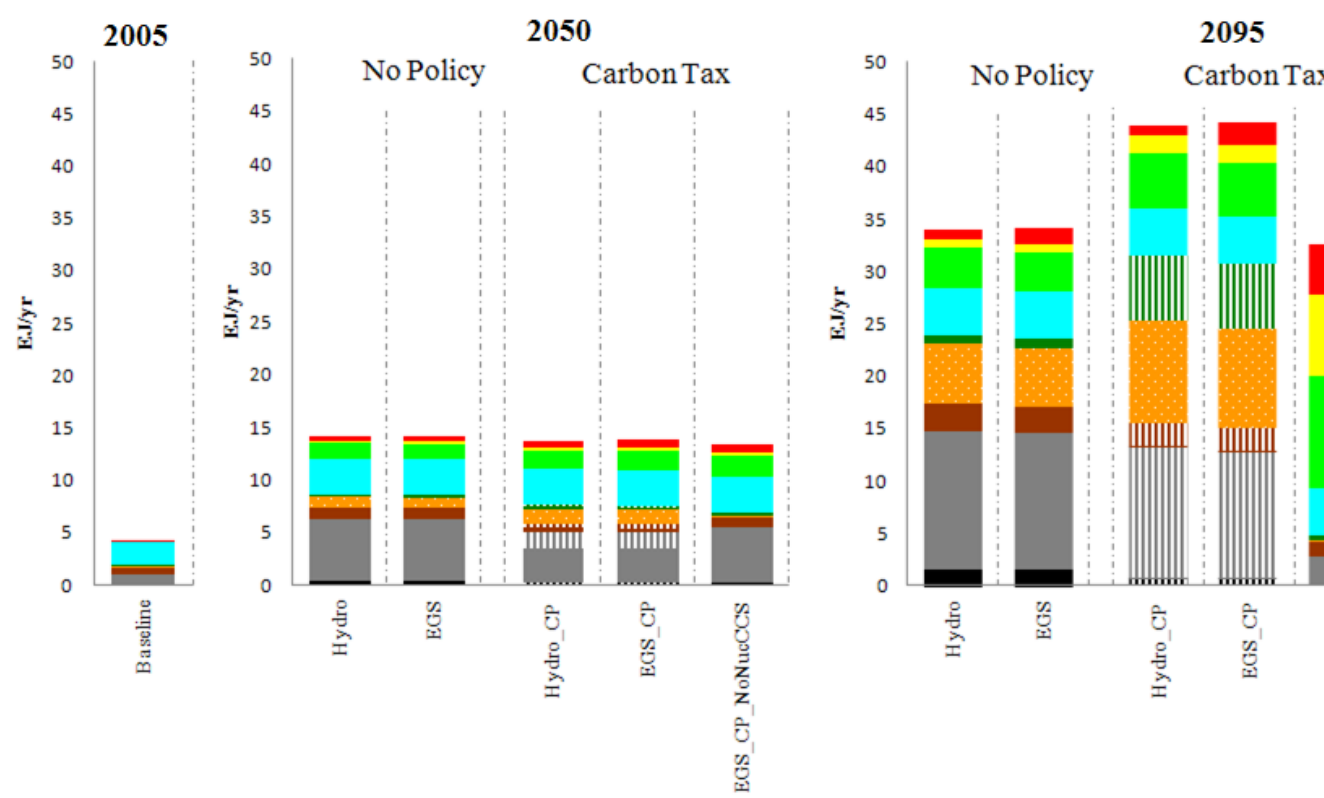

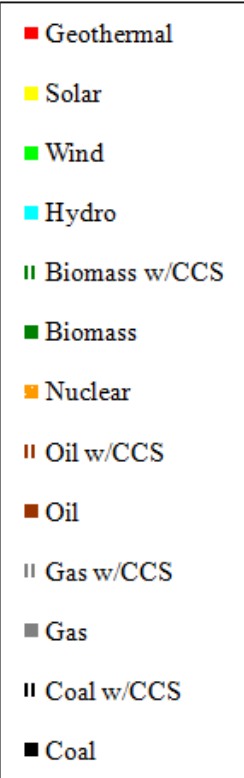

Figure 10: Southeast Asia (above) and Latin America (below) electricity generation by technology showing impact of policy on geothermal generation and grid share

In China and India, two nations in which $\mathrm{CO}_{2}$ emissions are increasing rapidly and (absent political intervention) will likely continue to do so in the future, EGS has limited impacts in relation to growing energy demand. In China and India, ten times as much geothermal electricity is produced by 2095 when EGS is available, relative to when only hydrothermal technologies are available. However, geothermal with availability of EGS still accounts for less than 2 percent of the grid share in both regions by 2095. Neither a climate policy nor constraints 
on CCS and nuclear further stimulate geothermal growth in these regions. This result is interesting given that China and India both anticipate rapid growth in nuclear generation over the next several decades (World Nuclear Association 2009), and limiting such growth combined with a climate policy should place a premium on a low-carbon alternative like geothermal. Under the assumptions used here, however, the geothermal resource bases are small in these regions (see Table 4), and electricity demand growth is very high absent a policy. As a result, nearly all possible EGS resources are deployed in all scenarios, and in the scenarios with climate policy but without nuclear expansion or CCS, wind and solar account for the majority of generation (albeit at high cost).

This highlights a relevant point regarding the geothermal supply curves used in this study. The geothermal resource curves are assumed to be very steep as assumed resource limits are approached (see Figure 4). Regions that deploy most of their resources in any scenario, such as China, India, and Africa in the EGS_CP scenario, are in the "steep” part of the supply curve. Further increases in electricity prices will not lead to corresponding increases in deployment. The likelihood of this outcome is worth questioning. These scenarios assume that the "economic" potential in the Bertani dataset constitutes a physical limit; no effort was made to allow for high electricity prices to increase the resource bases in regions with high "theoretical" potential relative to "economic" potential. Moreover, each of these regions may have future population shifts, or breakthroughs in transmission, which could make currently remote resources economically viable. This should be noted in assessing the results discussed above; while India appears to have a very low resource base, and geothermal likely would not be a big part of the generation mix in any scenario, both China and Africa have high amounts of "theoretical" potential in the Bertani dataset. In the upcoming century, it is quite reasonable to posit that technological change over time might allow a further increase in the EGS resource base over time. Consistent with this suggestion, the IEA (2008) suggests that EGS resources may actually be as abundant in China as in the United States.

The GCAM region encompassing Australia and New Zealand did not consider the geographical divide that inhibits resource and demand-sharing between these countries. Australia is characterized by high electricity demand, but has only minor low-temperature geothermal resources, probably best suited for direct heating applications. New Zealand uses less electricity-approximately 15\% of the electricity demand of the two countries (IEA 2007b) but is believed to have copious economically available geothermal resources for electricity production. Disaggregation of these nations in the model might output higher shares of geothermal use in New Zealand and much less in Australia. Recognizing this limitation, the current model output suggests a share of $7 \%$ of electricity generation in Australia-NZ with availability of EGS and use of a carbon price. Geothermal's share of the electricity grid is a quarter of total generation when nuclear and CCS technology deployment are constrained.

The implication of this result points to general issue that the model may be overestimating geothermal potential for some regions. In general, each of the regions discussed here rely on aggregated resources and generalized electricity demands. EGS resources, though more widely available and distributed than hydrothermal resources, must still be developed at the resource site, and therefore will rely on transmission to bring electricity to demand centers. Some areas within the fourteen diverse, aggregated, model regions could receive a higher or lower than average geothermal grid-share. However, because geothermal power plants produce baseload electricity, it is entirely reasonable for geothermal to supply a large portion of total electricity in the sub-regions where it is available. For instance, a recent assessment of U.S. 
geothermal market concluded that with current (hydrothermal) technology, geothermal could supply 60 percent of Nevada's electricity needs (Glitnir 2007). Due to its enhanced geographic availability, compared with hydrothermal resources, it follows that EGS would expand the number of such sub-regions that could potentially rely on geothermal for a majority of their electricity. Siting of EGS technology in particular may also be flexible enough such that generation can be located convenient to transmission capacity. Therefore, while the analysis presented in this report does not explicitly disaggregate geothermal resources into the subregions where they could economically be produced, there is no reason to believe that this issue biases the results in any particular direction. Geothermal energy, unlike existing wind or solar technologies, could also feasibly supply a very large portion of a sub-regional electricity grid without presenting systems management challenges.

\section{Conclusions}

\subsection{Findings}

Even without a climate policy or availability of enhanced geothermal systems (EGS), a large increase in geothermal energy production is seen in all scenarios in this analysis over the next few decades, under assumptions that costs continue to decrease, and that these technologies can be financed at rates comparable to other electric generation technologies. In the U.S. and most other global regions with geothermal potential, hydrothermal geothermal generation grows substantially between 2005 and 2050, but only slightly between 2050 and 2095 because resource limitations are reached. A climate policy does little to further incentivize already economical, but limited, geothermal resources. As an exception, Latin American hydrothermal deployment grows through 2095 and increases even further in response to a climate policy. In sum, hydrothermal can play an increasingly important role in global low-carbon energy development in the short term, but is not abundant enough to track long term demand even with a very high carbon price.

The development and deployment of EGS could cause a major change in the role of geothermal energy in U.S. and global energy systems. EGS allows for geothermal generation to grow substantially, beyond the more limited hydrothermal potential. In the U.S., for instance, availability of EGS results in twice as much geothermal deployment by 2095, even without a climate policy. The combination of a global climate policy and availability of EGS could also stimulate large deployments of geothermal energy relative to regional generation in Southeast Asia, Latin America and Western Europe. Under this case, India, Africa, China, Former Soviet Union, Australia and New Zealand, and Japan experience moderate levels of geothermal deployment. Additionally, unlike hydrothermal, the presence of a climate policy appears to stimulate significant additional deployment of EGS resources.

Constraining the use of nuclear and CCS in the U.S. results in geothermal producing over a quarter of U.S. electricity by 2095 - a strong indicator of this technology's potential competitiveness with a high carbon price and constraints on other readily available low-carbon alternatives. In such a case, geothermal electricity generation could account for 5 percent of global electricity generation by 2050, increasing to 10 percent by 2095. Significant resource constraints on wind and solar, or steeper carbon costs, would likely further accelerate growth in EGS. Constraints on nuclear energy and CCS technology do not increase geothermal deployment in all regions; India, China, and Africa all showed very little response to this model constraint under the assumptions used here. 


\subsection{Some obstacles of advanced geothermal technology deployment}

In considering the validity of the model results in this paper, it is important to realize that the projected growth of geothermal energy and EGS, in particular, depends on cost reductions and demonstrated reliability on a commercial scale in terms of predicable performance and future costs. Consequently, continued R\&D is important to help EGS achieve such a breakthrough.

EGS is a less proven technology with more uncertain costs. Some of the variables include: longevity of wells, predictability of siting and performance, and predictability of water consumption. Many of the advances in petroleum prospecting and extraction technology are relevant for EGS, although there are issues specific to EGS that warrant further consideration.

Hydrothermal generation in particular can result in emissions of geologic $\mathrm{CO}_{2}$ and other non-condensable gases such as hydrogen sulfide, methane, hydrogen, sulfur dioxide and ammonia in low concentrations, which are carried in the source steam (MIT 2006). $\mathrm{CO}_{2}$ emissions from geothermal are only a fraction of emissions from coal, oil and natural gas (see MIT 2006, Table 8.1), but can be mitigated with appropriate plant technologies such as closed loop power cycles. EGS is expected to have no GHG emissions, and fewer other emissions than even hydrothermal.

For EGS deployment, the impact of well creation and heat extraction (through a process called hydrocracking on the rock bed) may locally increase seismic activity. In one case, an EGS application in Basel, Switzerland, may have triggered a series of small earthquakes. While not severely damaging, these tremors were evidently of a type that was highly noticeable and caused substantial minor damage and annoyance. It is possible that the nature of geological structures in some regions could limit EGS applicability. Further research and investigation of potential seismic issues is warranted.

As with any thermal plant, local water availability may be an issue for geothermal plant siting. This is particularly the case for EGS, since there are significant water losses associated with cycling water through the hot rock fissures.

Additionally, deployment of EGS technology on any appreciable scale in developing countries may require an affordable transfer of the technology from developed countries where most research is currently located. Financing mechanisms that allow for up-front capital financing of EGS projects, as well as technical assistance for maintaining complex EGS operations, may be needed for deployment and sustained production. Low-carbon electricity alternatives like EGS will be necessary for achieving economic growth and electricity access goals sought by government in developing countries. Technologies allowing these countries to reduce their emissions intensity may also facilitate objectives created under a global climate cap, while also reducing the marginal cost of abatement through carbon finance from developed nations.

Despite these apparent obstacles, other additional benefits not discussed in this report may enhance the suitability of EGS as a zero-carbon energy alternative. Land use requirements of geothermal facilities are oftentimes a fraction of coal, nuclear and solar thermal and PV facilities (MIT 2006, Table 8.2). The footprint of the geothermal wellhead and associated equipment is small, and steam pipelines can be raised to allow use of the site as pasturelands or 
for additional land uses. Additionally, there may be potential for using supercritical $\mathrm{CO}_{2}$ from fossil or biomass sources as the heat transfer fluid in EGS. Thermodynamic advantages of supercritical $\mathrm{CO}_{2}$ over water, as well as reduced water consumption, make this an attractive possibility. Porous rock used with supercritical $\mathrm{CO}_{2}$ EGS systems may result in major fluid losses and permanent geological carbon sequestration (Brown 2000; MIT 2006), thus giving EGS a further cost advantage under a carbon pricing scenario. If technological barriers can be overcome, EGS is positioned to play a significant role in global low-carbon energy development. 


\section{References}

Brown, D.W. 2000. A hot dry rock geothermal energy concept utilizing supercritical $\mathrm{CO}_{2}$ instead of water.” Paper SGP-TR-165, Proceedings of the Twenty-Fifth Workshop on Geothermal Reservoir Engineering, Stanford University, Stanford, CA.

Brenkert, A., Smith, S., Kim, S., Pitcher, H., 2003. Model Documentation for the MiniCAM. PNNL-14337, Pacific Northwest National Laboratory, Richland WA. http://www.pnl.gov/main/publications/external/technical_reports/PNNL-14337.pdf

Chandler, W., Gwin, H., 2008. Financing Energy Efficiency in China. Carnegie Endowment for International Peace, Washington, D.C. http://www.carnegieendowment.org/files/chandler_clean_energy_final.pdf

Clarke, J,F, Edmonds, J.A., 1993. Modeling energy technologies in a competitive market. Energy Economics 15, 123-129.

Clarke, L., Wise, M.A., Edmonds, J., Placet, M., Kyle, P., Calvin, K., Kim, S., Smith, S., 2008a. $\mathrm{CO}_{2}$ Emissions Mitigation and Technological Advance: an Updated Analysis of Advanced Technology Scenarios (Scenarios Updated January 2009). PNNL-18075, Pacific Northwest National Laboratory, Richland, WA. http://www.pnl.gov/science/pdf/PNNL18075.pdf

Clarke, L., Weyant, J., Edmonds, J., 2008b. On sources of technological change: what do the models assume? Energy Economics 30, 409-424.

Deloitte, 2008. Geothermal Risk Mitigation Strategies Report. Deloitte Development LLC. Prepared for Office of Energy Efficiency and Renewable Energy Geothermal Program, U.S. Department of Energy, Washington, D.C. http://www1.eere.energy.gov/geothermal/pdfs/geothermal_risk_mitigation.pdf

EIA, 2009. Approximate Heat Rates for Electricity, and Heat Content of Electricity, Selected Years, 1949-2008. Table A6 in: Annual Energy Review 2008, Energy Information Administration, U.S. Department of Energy, Washington, D.C. http://www.eia.doe.gov/emeu/aer/pdf/pages/sec13_6.pdf

Glitnir, 2007. United States Geothermal Energy Market Report. Glitnir Geothermal Research. http://docs.glitnir.is/media/files/Glitnir_USGeothermalReport.pdf

IEA, 2007a. Energy Balances of Non-OECD Countries, 1971-2005. International Energy Agency, Paris, France.

IEA, 2007b. Energy Balances of OECD Countries, 1960-2005. International Energy Agency, Paris, France.

IEA, 2008. Geothermal Energy Annual Report, 2006. Implementing Agreement for Cooperation in Geothermal Research \& Technology, International Energy Agency, Paris, France.

IPCC, 2007. Climate Change 2007: Synthesis Report. Pachauri, R.K., Reisinger, A. (eds.). Contribution of Working Groups I, II, and III to the Fourth Assessment Report of the Intergovernmental Panel on Climate Change. http://www.ipcc.ch/ipccreports/ar4-syr.htm 
Kim, S., Edmonds, J., Lurz, J., Smith, S., Wise, M., 2006. The Object-oriented Energy Climate Technology Systems (ObjECTS) framework and hybrid modeling of transportation in the MiniCAM long-term, global integrated assessment model. The Energy Journal, Special Issue: Hybrid Modeling of Energy-Environment Policies: Reconciling Bottom-up and Top-down, 63-91.

MIT (2006). The Future of Geothermal Energy: Impact of Enhanced Geothermal Systems (EGS) on the United States in the $21^{\text {st }}$ Century. Massachusetts Institute of Technology, Cambridge, MA. http://geothermal.inel.gov

Petty, S., Porro, G., 2007. Updated U.S. Geothermal Supply Characterization. Conference Paper NREL/CP-640-41073, National Renewable Energy Laboratory, Golden, CO.

U.S. DOE, 2008. 20 percent Wind Energy by 2020, Increasing Wind Energy's Contribution to U.S. Electricity Supply. DOE/GO-102008-2567. Office of Energy Efficiency and Renewable Energy, U.S. Department of Energy, Washington, D.C. http://www1.eere.energy.gov/windandhydro/pdfs/41869.pdf

World Bank, 2008. State and Trends of the Carbon Market 2008. http://siteresources.worldbank.org/NEWS/Resources/State\&Trendsformatted06May10p $\underline{\text { m.pdf }}$

World Nuclear Association, 2009. World Nuclear Power Reactors 2007-2009 and Uranium Requirements. http://www.world-nuclear.org/info/reactors.html 


\section{Appendix: Electricity Generation by Region and Scenario}

USA Electricity Generation by Aggregate Technology

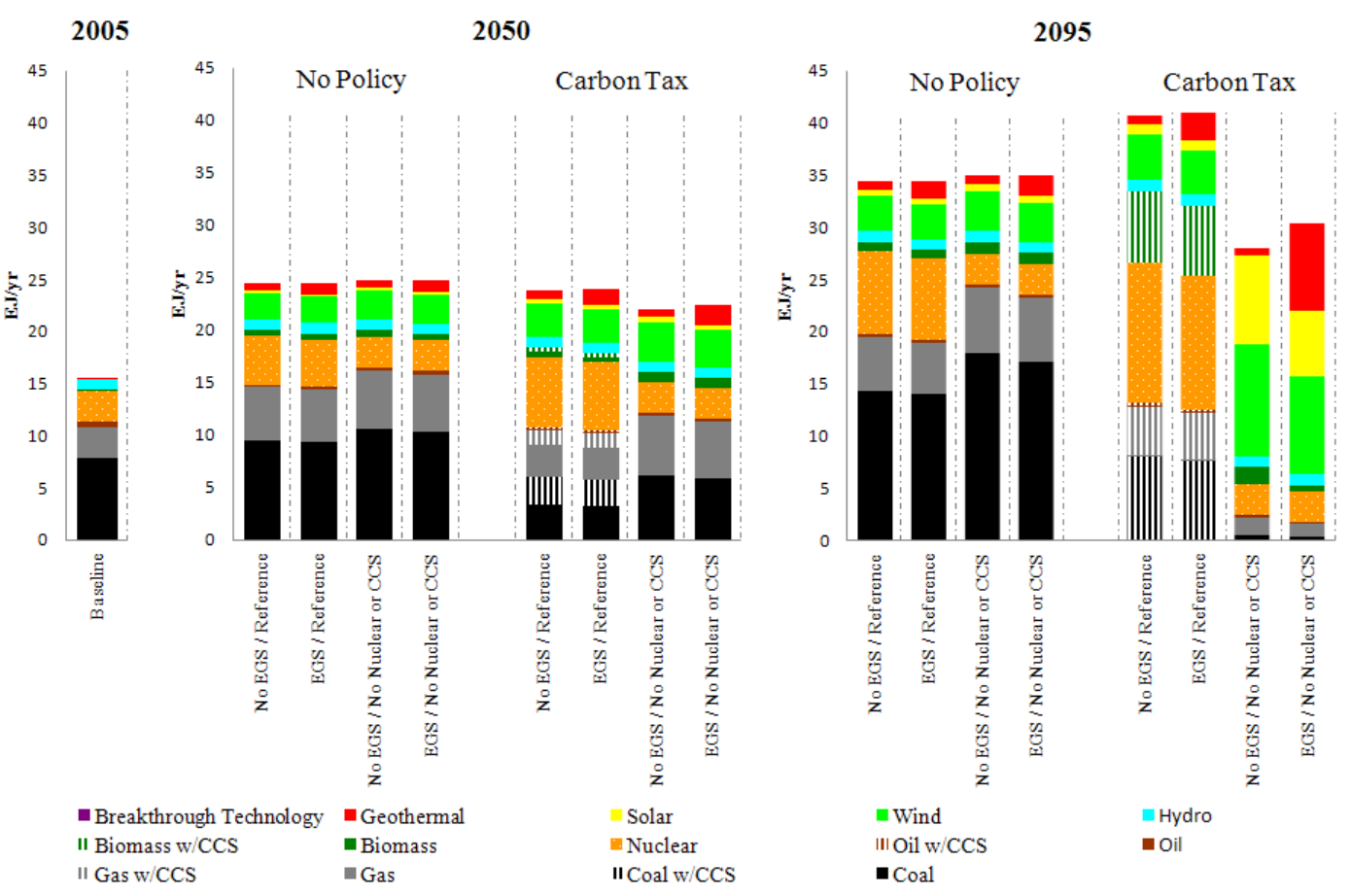

Canada Electricity Generation by Aggregate Technology

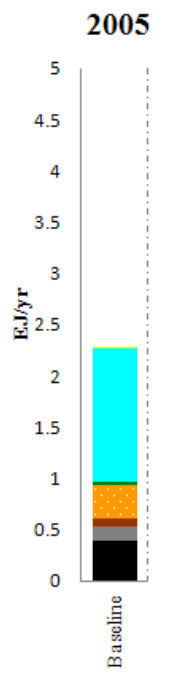

5
4.5
4
3.5
3
5
2.5
2
1.5
1
0.5
0

2050

No Policy

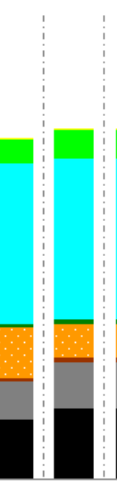

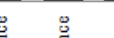

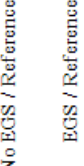

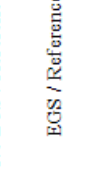

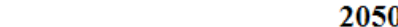

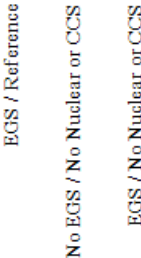

- Breakthrough Technology

II Biomass w/CCS

II Gas w/CCS
- Geothermal

- Biomass

$\because \mathrm{Gas}$
Carbon Tax

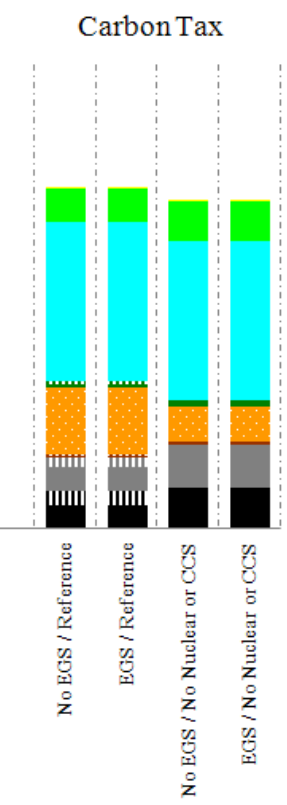

Solar

Nuclear

II Coal w/CCS

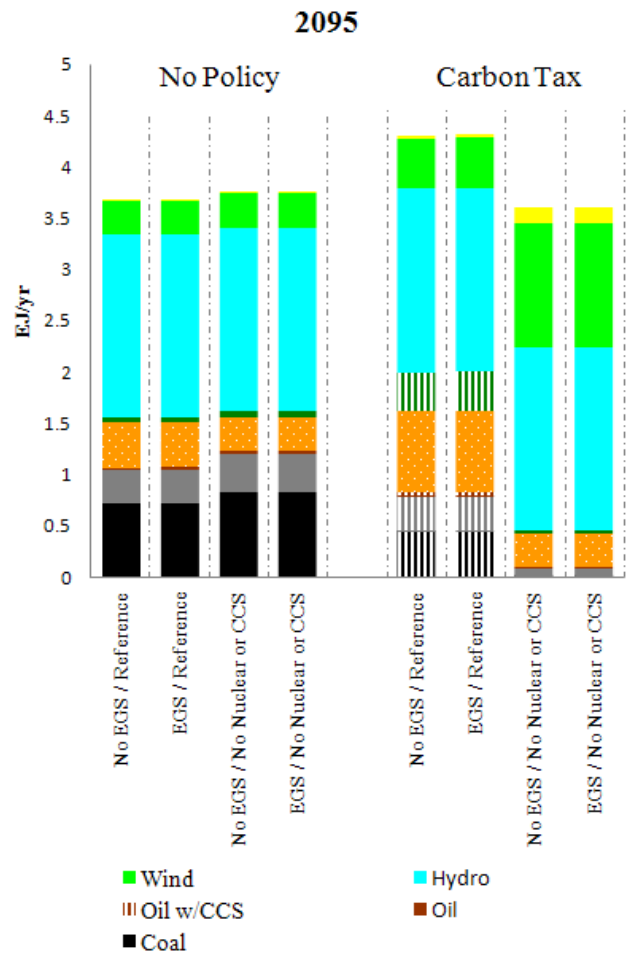




\section{Western Europe Electricity Generation by Aggregate Technology}

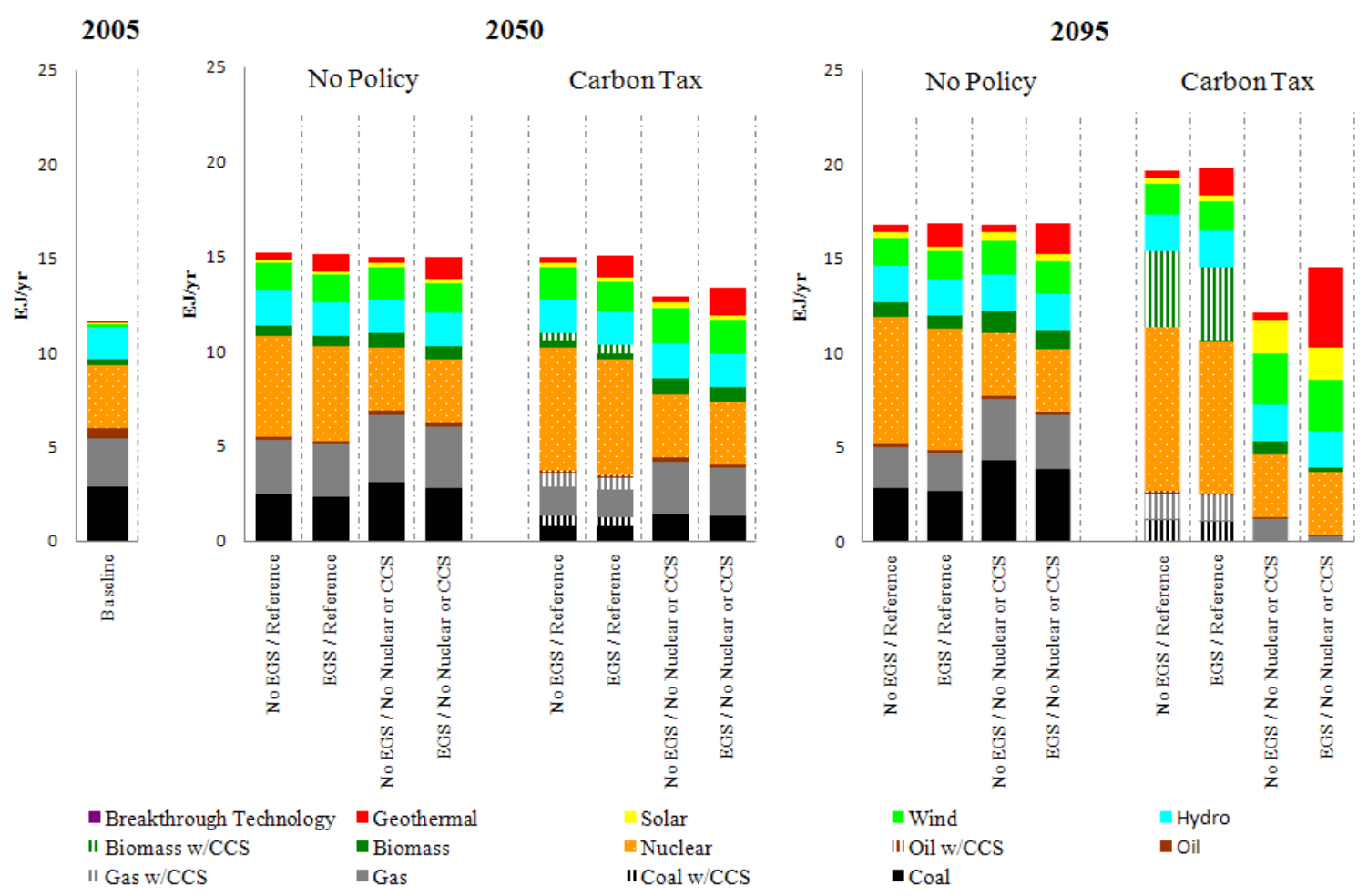


Japan Electricity Generation by Aggregate Technology

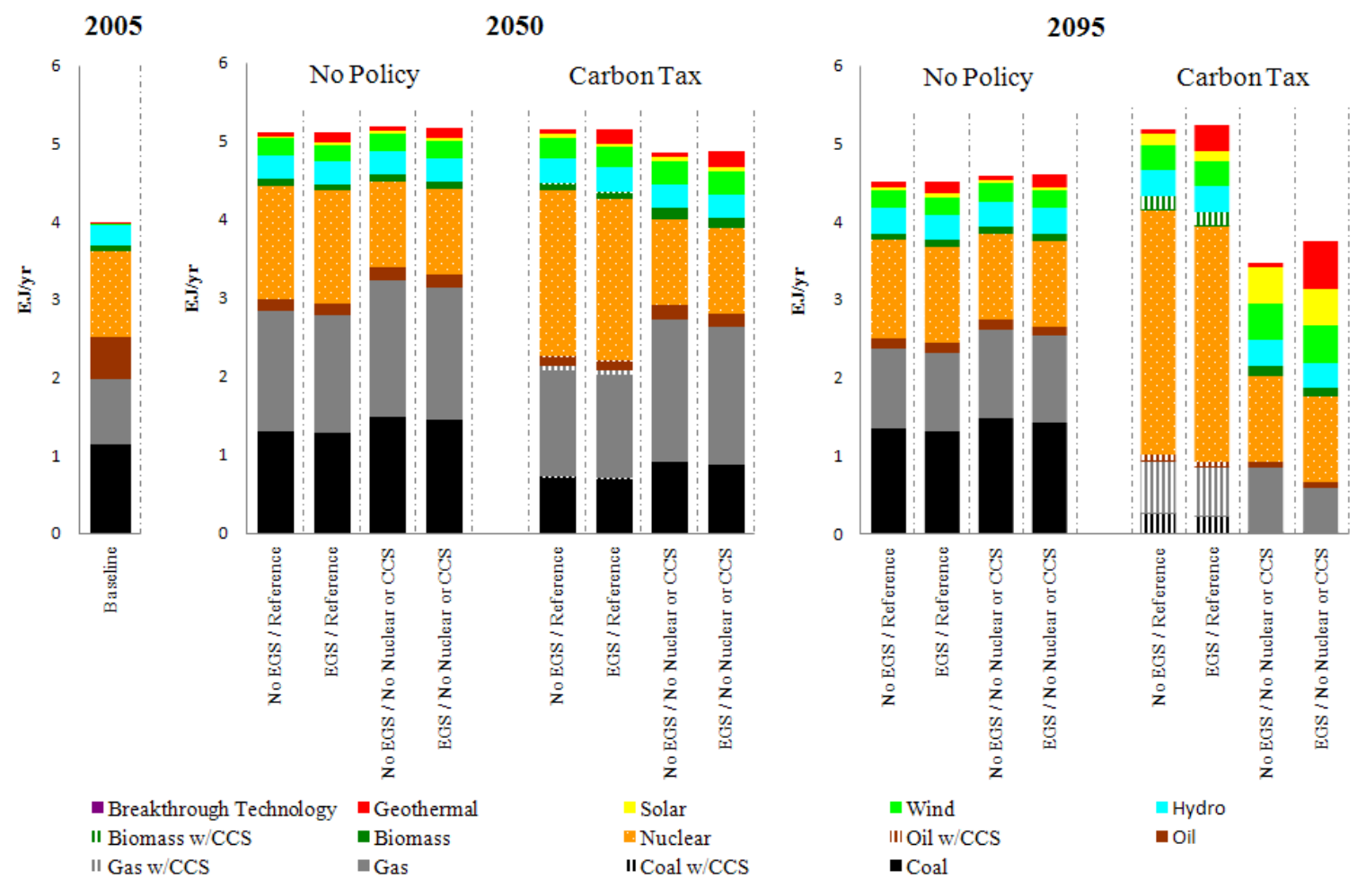




\section{New Zealand Electricity Generation by Aggregate Technology}

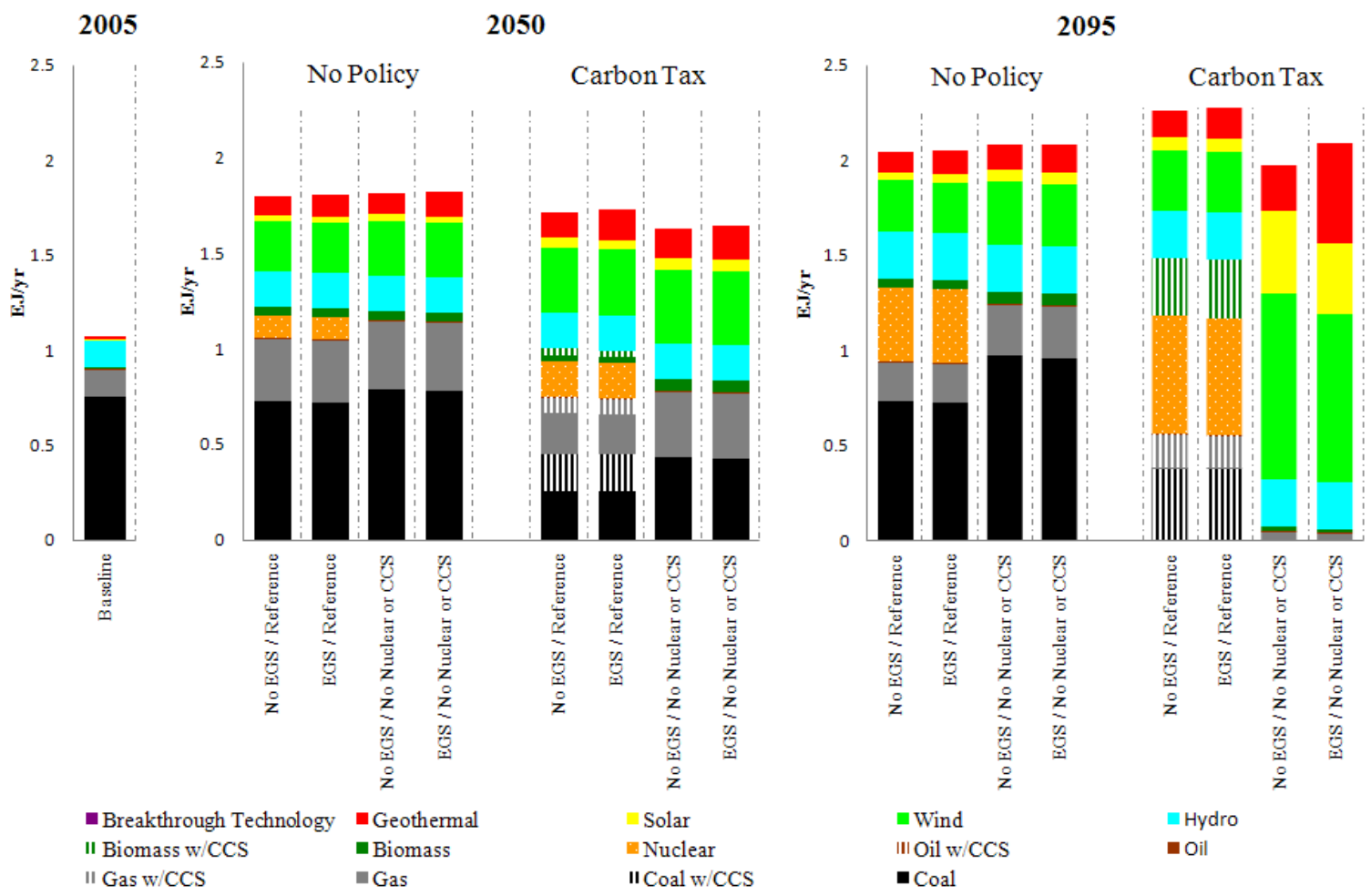

Former Soviet Union Electricity Generation by Aggregate Technology

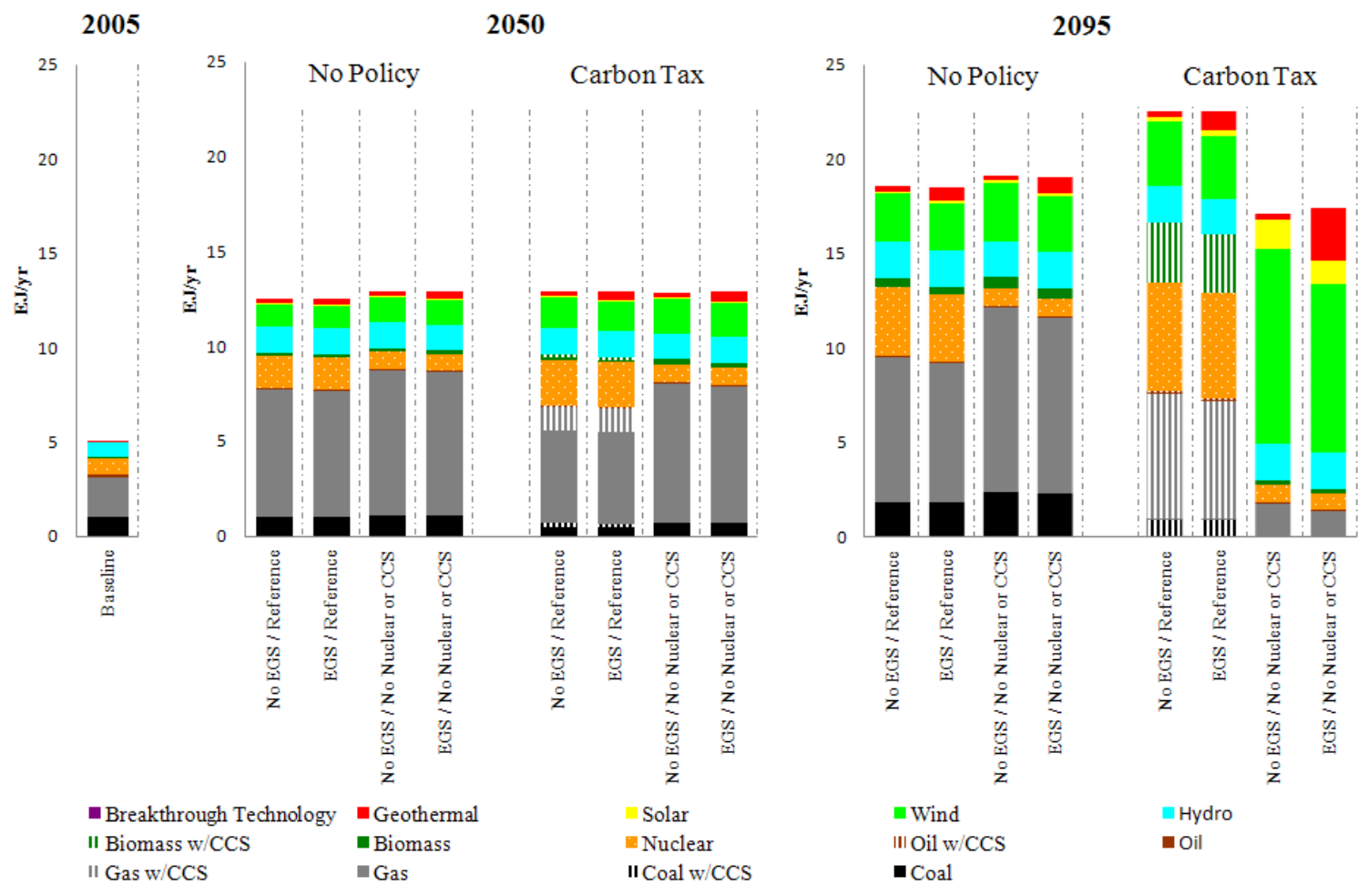




\section{China Electricity Generation by Aggregate Technology}

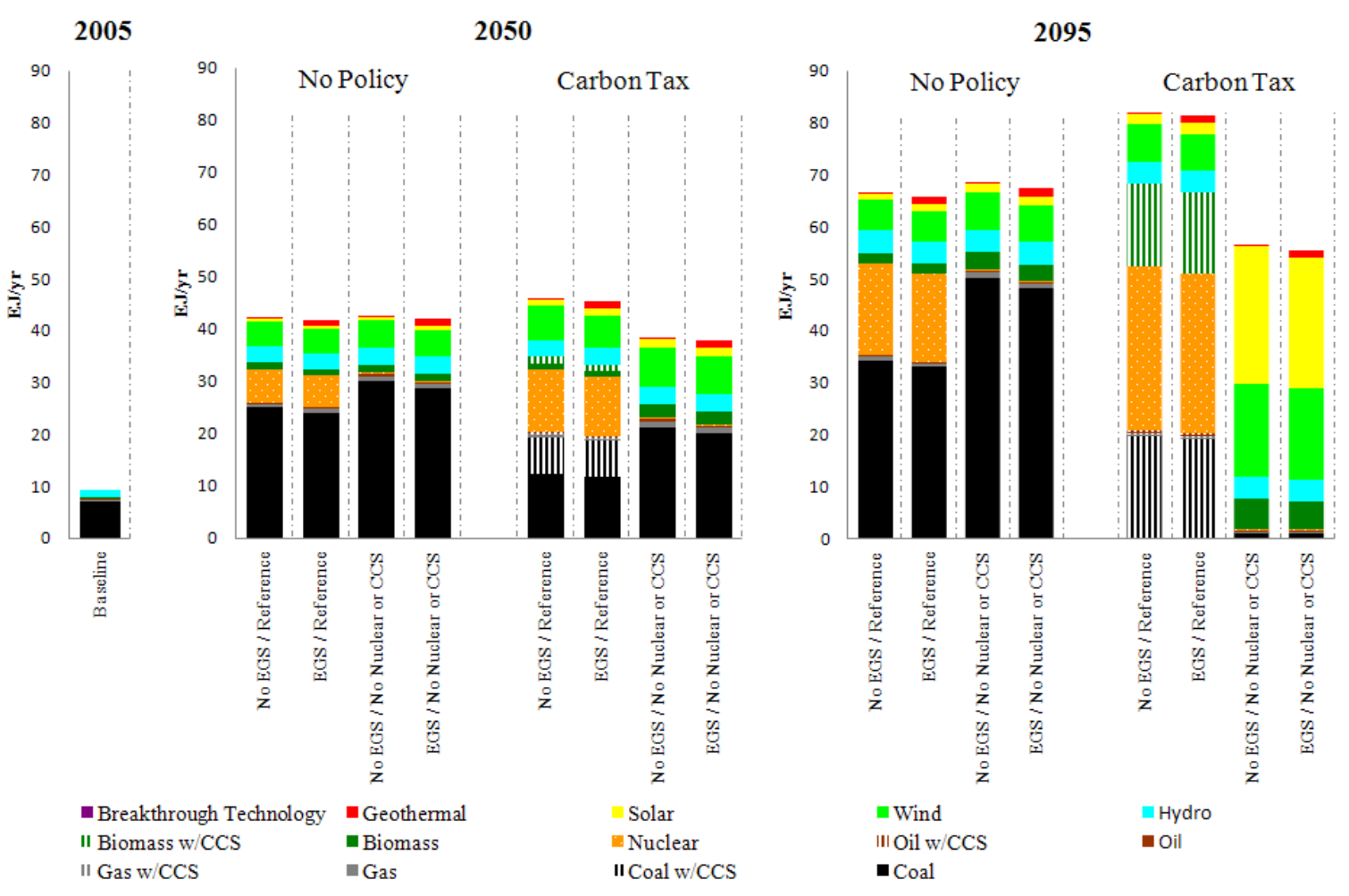


Middle East Electricity Generation by Aggregate Technology
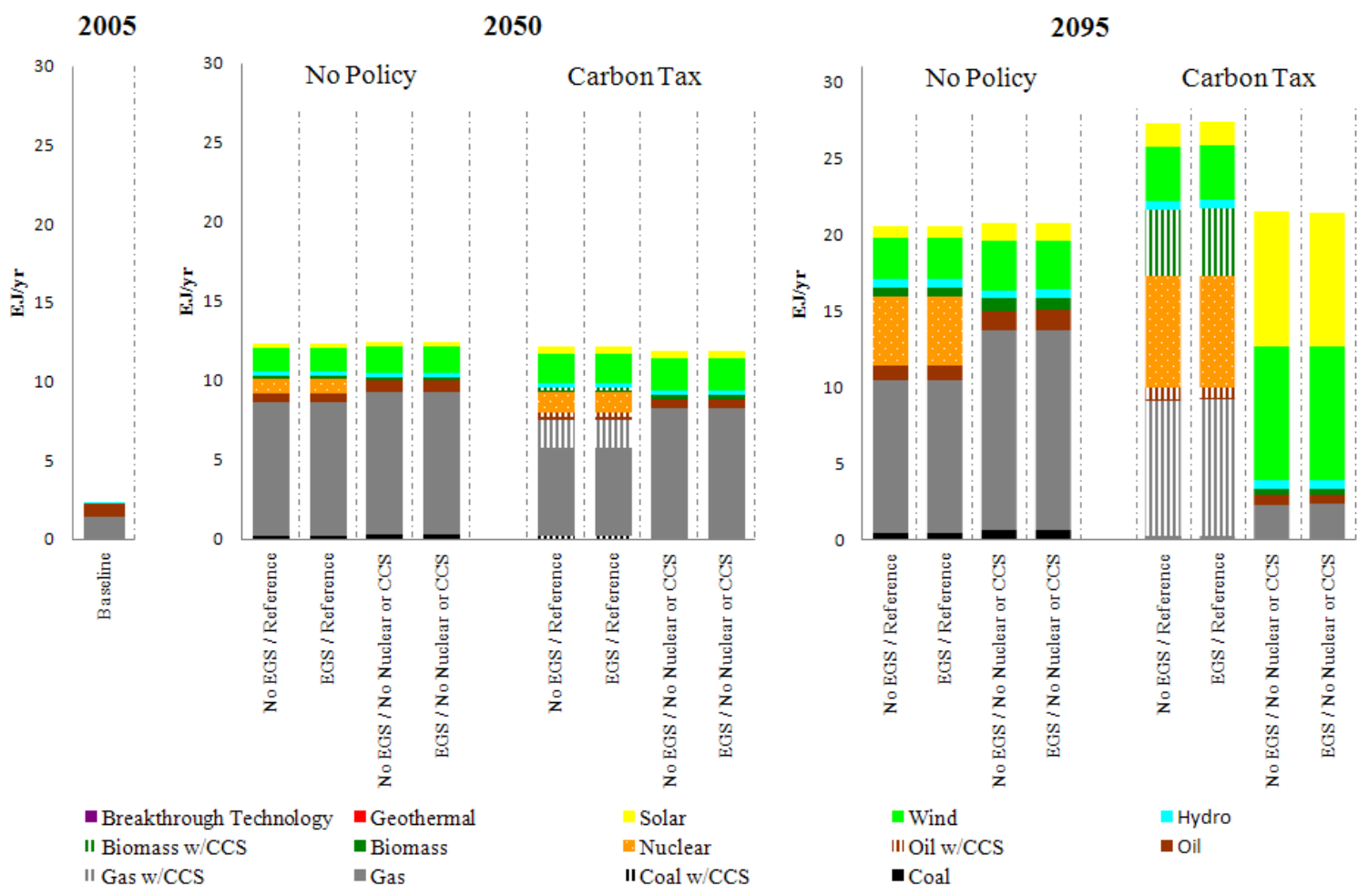

Africa Electricity Generation by Aggregate Technology

2005

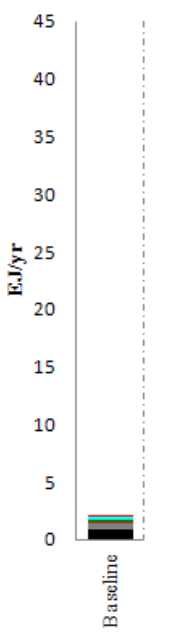

2050

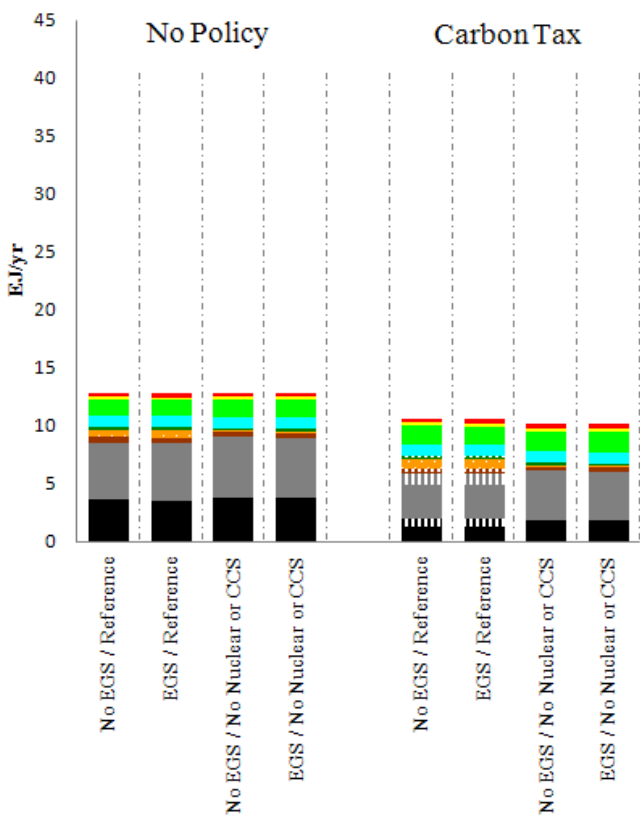

- Breakthrough Technology Geothermal

II Biomass w/CCS

- Biomass

II Gas w/CCS mas

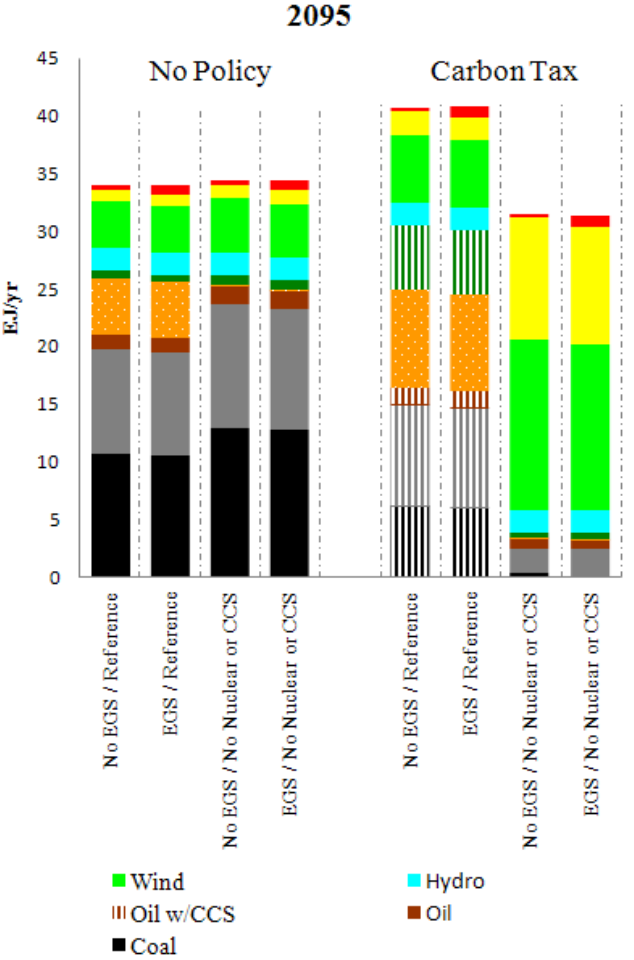




\section{Latin America Electricity Generation by Aggregate Technology}
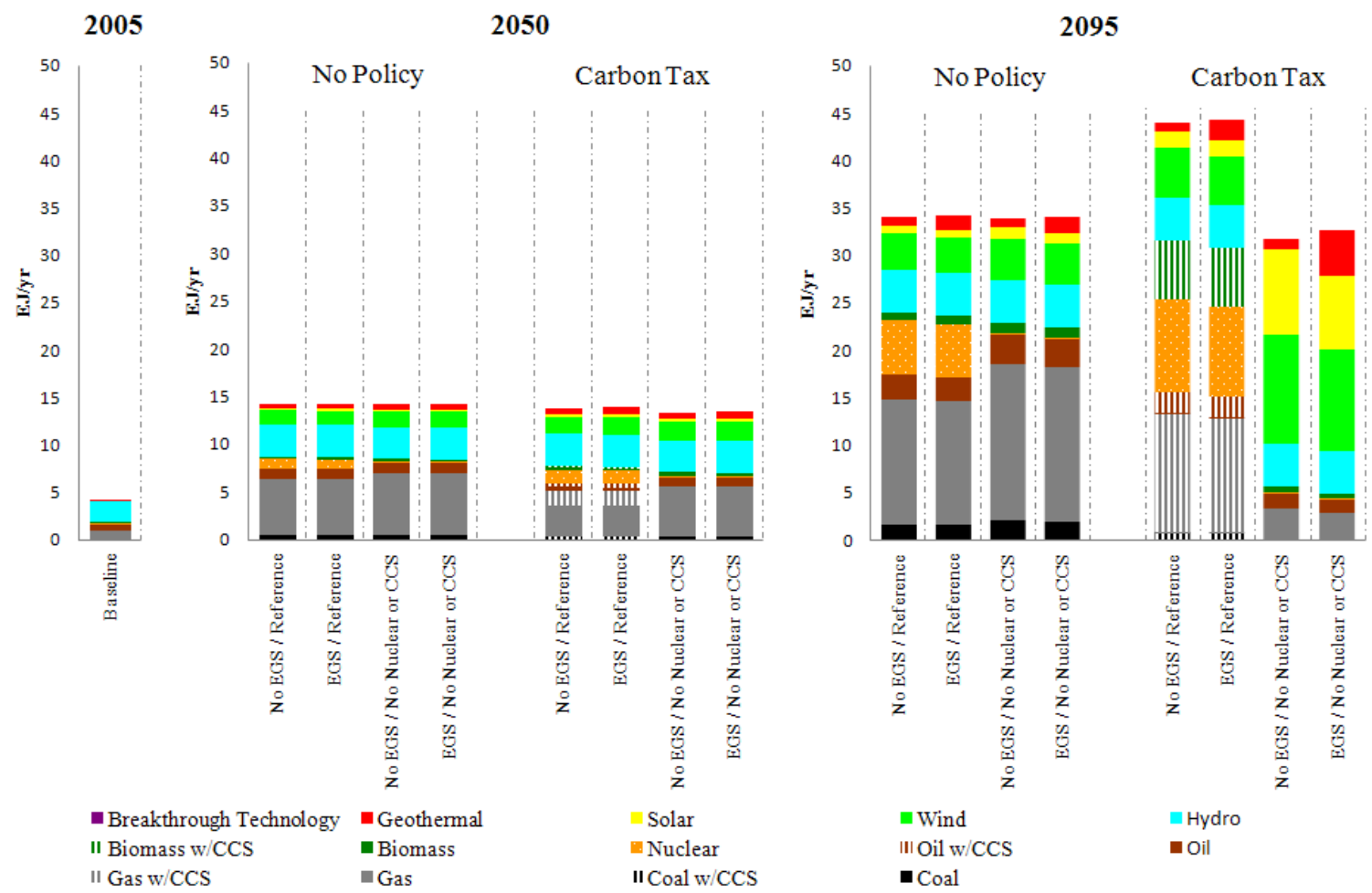

Southeast Asia Electricity Generation by Aggregate Technology
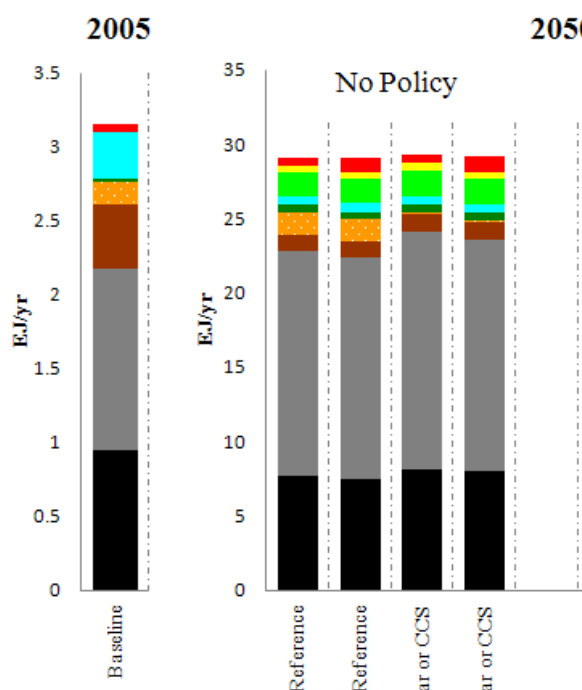

2050

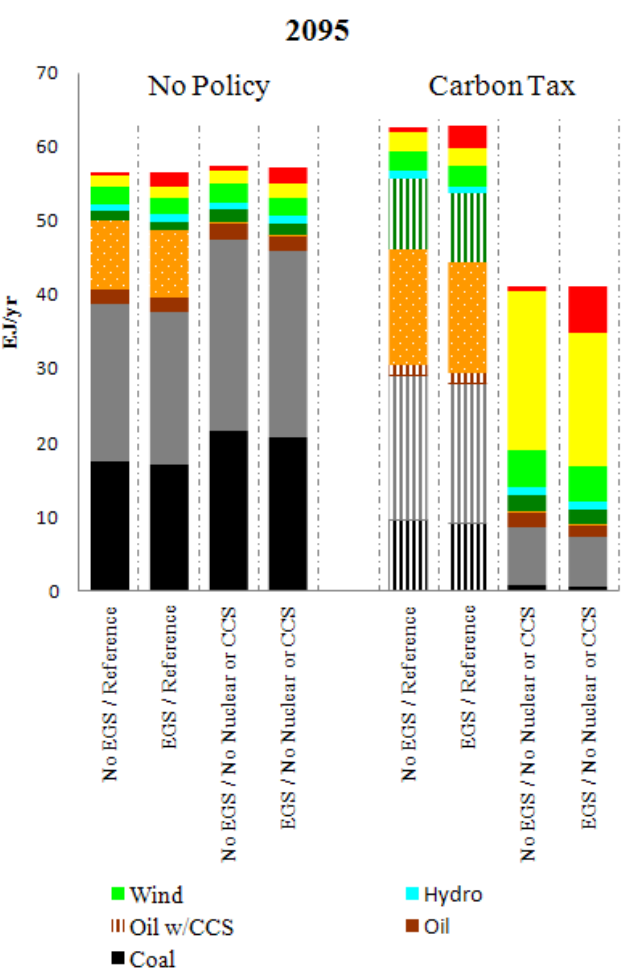




\section{Eastern Europe Electricity Generation by Aggregate Technology}

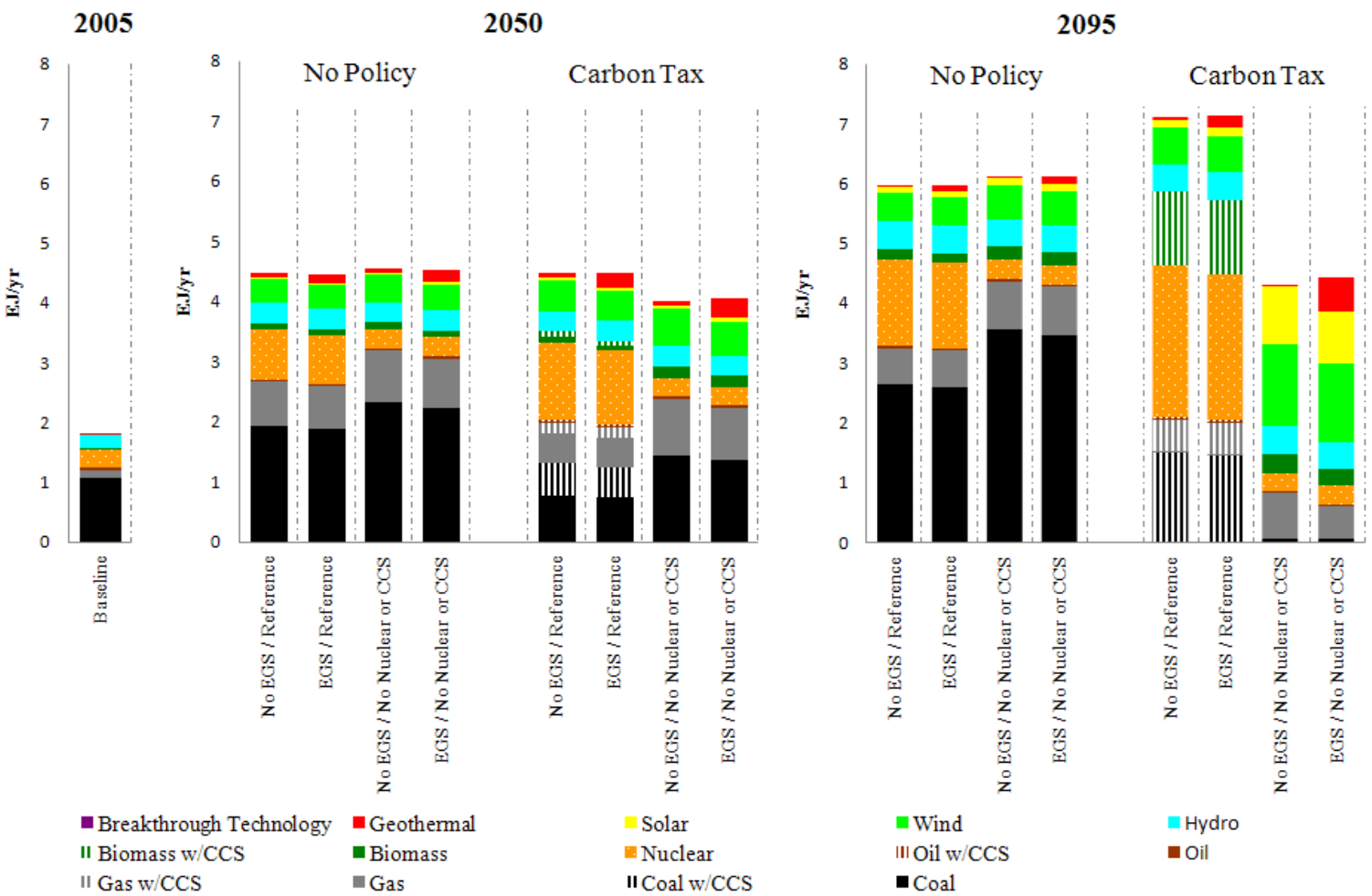

Korea Electricity Generation by Aggregate Technology

2005

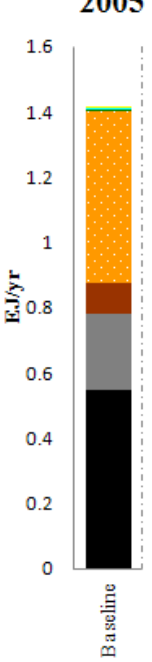

2050

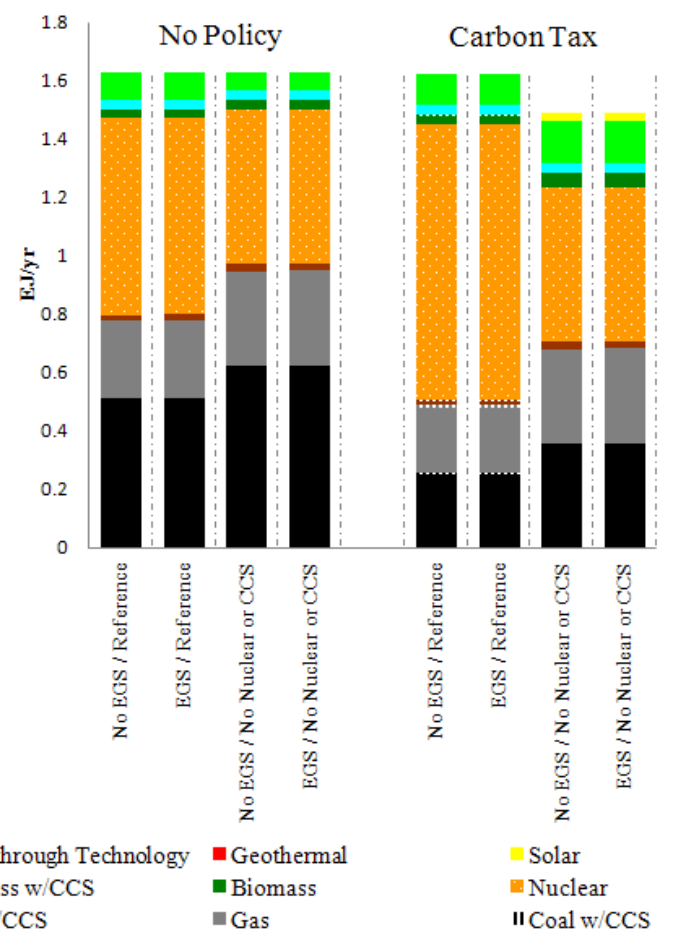

2095

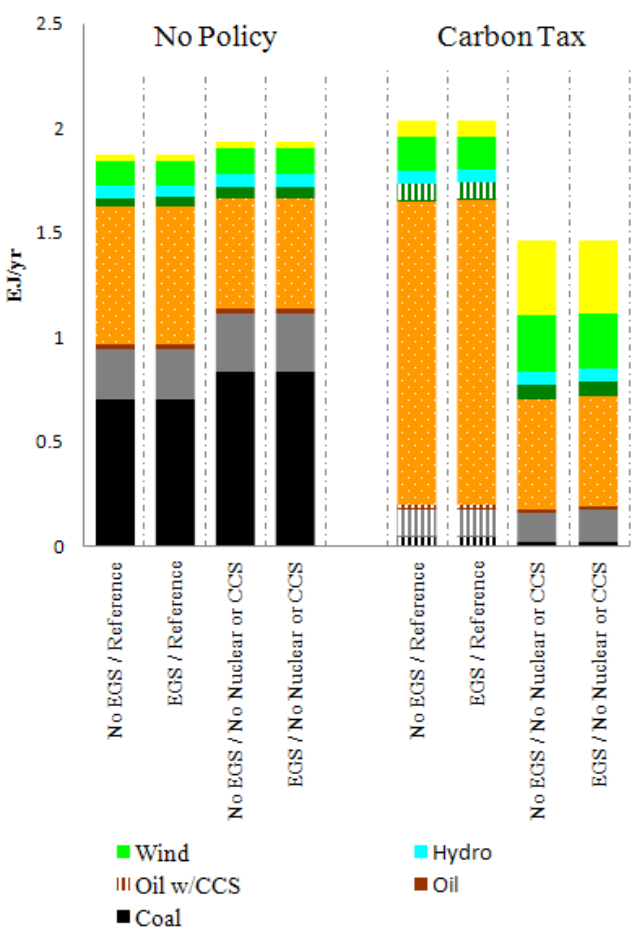


India Electricity Generation by Aggregate Technology
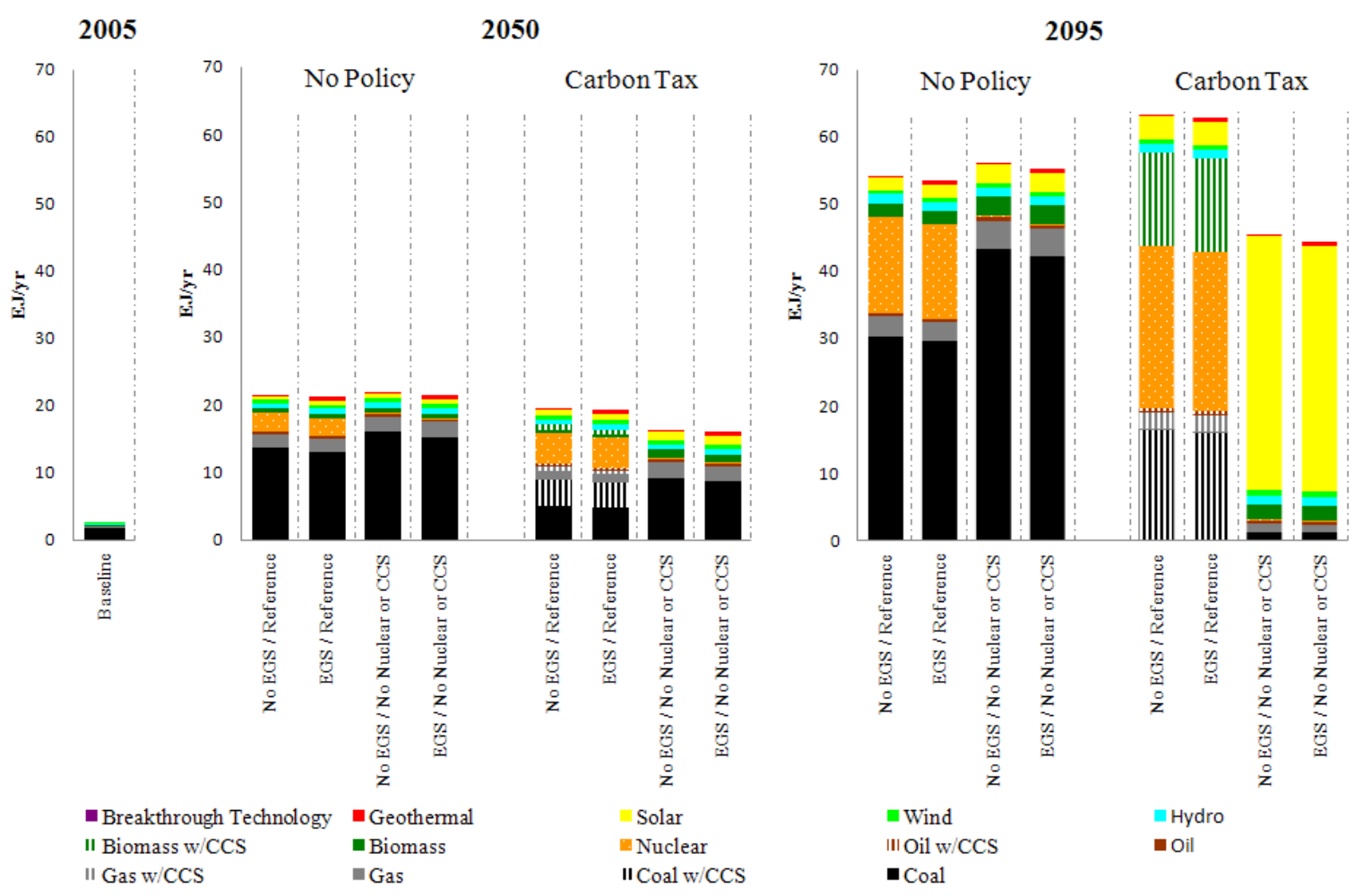